\title{
3D Self-Supported Nanoarchitectured Arrays Electrodes for Lithium-Ion Batteries
}

\author{
Xin Chen, ${ }^{1}$ Ying Du, ${ }^{1,2}$ Nai Qing Zhang, ${ }^{2,3}$ and Ke Ning Sun ${ }^{2,3}$ \\ ${ }^{1}$ Department of Chemistry, Harbin Institute of Technology, Harbin, Heilongjang 150001, China \\ ${ }^{2}$ Academy of Fundamental and Interdisciplinary Sciences, Harbin Institute of Technology, Harbin, Heilongjang 150001, China \\ ${ }^{3}$ State Key Laboratory of Urban Water Resource and Environment, Harbin Institute of Technology, Harbin, \\ Heilongjang 150001, China
}

Correspondence should be addressed to Ke Ning Sun, keningsun@yahoo.com.cn

Received 17 October 2012; Accepted 3 December 2012

Academic Editor: Jianmin Ma

Copyright ( $) 2012$ Xin Chen et al. This is an open access article distributed under the Creative Commons Attribution License, which permits unrestricted use, distribution, and reproduction in any medium, provided the original work is properly cited.

Three-dimensional self-supported nanoarchitectured arrays electrodes (3DSNAEs) consisting of a direct growth of nanoarchitectured arrays on the conductive current collector, including homogeneous and heterogeneous nanoarchitectured arrays structures, have been currently studied as the most promising electrodes owing to their synergies resulting from the multistructure hybrid and integrating heterocomponents to address the requirements (high energy and power density) of superperformance lithium ion batteries (LIBs) applied in portable electronic consumer devices, electric vehicles, large-scale electricity storage, and so on. In the paper, recent advances in the strategies for the fabrication, selection of the different current collector substrates, and structural configuration of 3DSNAEs with different cathode and anode materials are investigated in detail. The intrinsic relationship of the unique structural characters, the conductive substrates, and electrochemical kinetic properties of 3DSNAEs is minutely analyzed. Finally, the future design trends and directions of 3DSNAEs are highlighted, which may open a new avenue of developing ideal multifunctional 3DSNAEs for further advanced LIBs.

\section{Introduction}

Currently, extensive concern about the increasingly worsened environmental pollution and impending exhaustion of limited energy resources has brought about the ever-going demand for seeking renewable and clean energy sources to cope with these serious energy and environmental issues [13]. As a suitable energy source, lithium ion batteries (LIBs) are being exploited for the widespread applications [4-7] in portable electronic consumer devices, electric vehicles, and large-scale electricity storage in intelligent grids, due to the multiple superiorities such as high energy density, safety, long life, low cost, and environmental benignity.

A typical commercial LIB consists of a positive electrode (cathode) formed from layered $\mathrm{LiCoO}_{2}$, a nonaqueous liquid electrolyte, and a graphite negative electrode (anode) in Figure 1(a). During the charging process, lithium ion $\left(\mathrm{Li}^{+}\right)$is deintercalated from the layered $\mathrm{LiCoO}_{2}$ host, passes through the electrolyte, and is intercalated between the graphite layers. Vice versa, discharge reverses this process. The electrons, of course, pass across the external circuit [8]. To realize the charge and discharge, the commercial LIBs are commonly constructed by electrodes and the electrolyte trapped within a polypropylene separator, in which electrodes are fabricated by the slurry procedure involved in mixing active electrodes materials with conducting carbon and polymeric binders and then casting them onto the current collector in Figure 1(b).

The electrodes materials are rated on the basis of their specific (gravimetric) capacity $\left(\mathrm{mAh} \mathrm{g}^{-1}\right)$, determined by their charge/discharge graphs, and the degree of capacity change upon cycling at different demands. Intense scrutinized cathode materials, mainly including $\mathrm{LiCoO}_{2}$, $\mathrm{LiMn}_{2} \mathrm{O}_{4}, \mathrm{LiNi}_{x} \mathrm{Mn}_{y} \mathrm{Co}_{z} \mathrm{O}_{2}, \mathrm{LiFePO}_{4}$, and $\mathrm{V}_{2} \mathrm{O}_{5}$ [9-13], have their own unique structured merits, offering highly accessible $\mathrm{Li}^{+}$diffusion pathways and demerits like limited specific capacities as well as poor capacity retention $[14,15]$. Anode materials, such as carbon, silicon, alloy, metal oxides, 


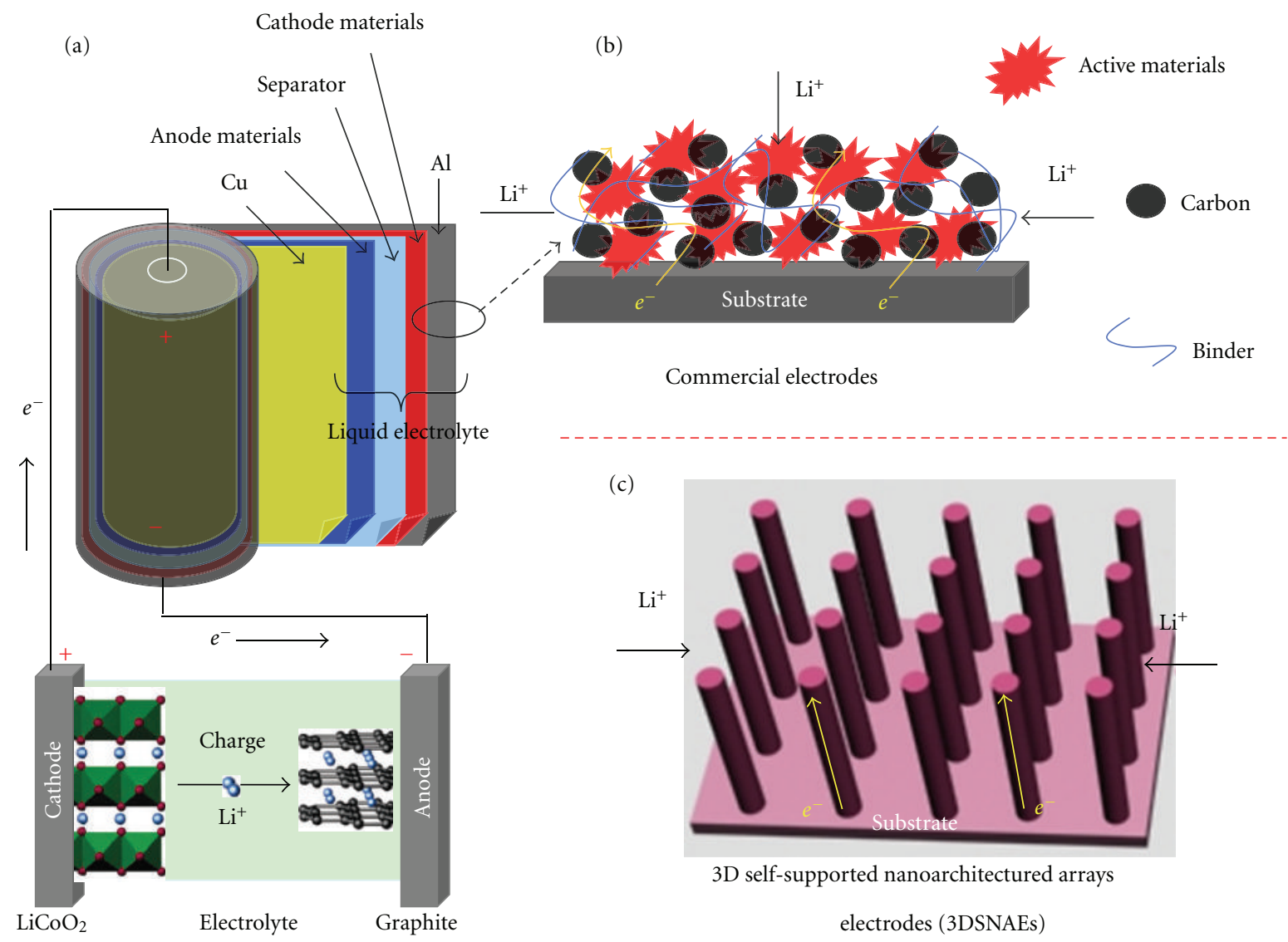

FIGURE 1: Schematic showing (a) operating principles and components of the typical commercial cylindrical lithium ion batteries (LIBs), (b) the slurry procedure of fabricating commercial electrodes, and (c) the configuration of novel 3D self-supported nanoarchitectured arrays electrodes (3DSNAEs).

and metal sulfides/phosphides, exhibit high capacities and couple to the poorly structured stability and volume variation issues [16-24]. No matter how creative researchers design new lithium intercalation materials, one drawback exists due to the intrinsic diffusivity of $\mathrm{Li}^{+}$in the solid state (ca. $10^{-8} \mathrm{~cm}^{2} \mathrm{~s}^{-1}$ ), which unavoidably limits the charge/discharge performance [25]. In this regard, many efforts have been devoted to devise a variety of nanomaterials with unique structures from zero-dimensional nanoparticles and one-dimensional (1D) nanowires to three-dimensional (3D) micro-/nanostructures and hollow- and core-shell structures, resulting in improved electrochemical performance to satisfy the demands of industrial applications [25-31].

These nanomaterials aforementioned have great superiorities [1, 32, 33] over their bulk counterparts. The reduced dimensions of materials shorten the $\mathrm{Li}^{+}$and electron transport length, leading to higher capacity at high rates. Meanwhile, a high surface area allows a large contact interface between the electrode material and electrolyte and enhances the $\mathrm{Li}^{+}$flux across the interface, resulting in a higher capacity. In addition, the small size could accommodate the strain associated with intercalation, reducing the capacity losses. However, nanomaterials are not a panacea to a certain extent and have some disadvantages $[34,35]$ such as more side reactions with the electrolyte due to the high electrolyte/electrode surface area, weak structure stabilities induced by aggregations, and lower volumetric energy density compared with microscale materials.

To transcend the above limitations of nanomaterials, selecting a proper approach, a proper structure, and a proper combination of various materials to assemble the active materials into the desired structures is indispensable. Recently, a novel configuration of 3D self-supported nanoarchitectured arrays electrodes (3DSNAEs) in Figure 1(c) has attracted much attention owing to the combination of diversified nanostructures' merits, including high surface in favor of high capacity, ordered and stable structures to the benefit of buffering for the volume change and improving the electric conductivity of electrodes, and lower aggregation and collapse in comparison to nanoparticles [36-38]. This kind of 3DSNAEs consists of a direct growth of nanoarchitectured arrays on the conductive current collector, providing a direct pathway for efficient charge transport along the arrays axis and forming a 3D conductive network among active materials, nanoarchitectured arrays pathways, and the conductive current collector. Differencing from the traditional slurry procedure, each nanoarchitectured array of 3DSNAEs is directly connected to the current-carrying substrate without any conductive and binder agents and allows for all 
structures' contribution to the capacity and efficient charge transport, leading to the excellent electrochemical properties $[37,39,40]$.

In this paper, detailed investigations are focused on strategies for the fabrication, selection of the different current collector substrates, and structural configuration of 3DSNAEs with different cathode and anode materials for LIBs. The intrinsic relationship of the unique structural characters, the conductive substrates, and electrochemical kinetic properties of 3DSNAEs is minutely analyzed, and recent work by our group is also summarized. Finally, the problems and prospects are highlighted on this kind of 3DSNAEs.

\section{Strategies for Fabrication}

Nanoarchitectured arrays of 3DSNAEs, including 1D nanowires (NWs), and nanotubes (NTs), nanorods (NRs), are apparently influenced by their properties of the conductive substrates, owing to the unique structures that nanoarchitectured arrays are directly grown on the current collector substrates. Different strategies, therefore, should be made to fabricate the 3DSNAEs grown on the different substrates. To the best of our knowledge, the conductive substrates applied in the 3DSNAEs principally contain $\mathrm{Al}$, $\mathrm{Cu}, \mathrm{Ti}, \mathrm{Ni}, \mathrm{Au}, \mathrm{Si}$, stainless steel (SS), Fe-based alloy, Sndoped $\operatorname{In}_{2} \mathrm{O}_{3}$ (ITO), and so on. And the strategies to fabricate 3DSNAEs may be classified into 3 categories in Figure 2, namely, self-growing, wet-etching, and template-based growth.

Self-growing in Figure 2(a) is the one for fabricating the nanoarchitectured arrays directly grown on the substrates by using a variety of techniques such as vapor phase growth, hydro-/solvothermal growth, and solution-based growth. Vapor phase growth including thermal chemical vapor deposition (CVD), direct thermal evaporation [41], and pulsed-laser deposition (PLD) is a straightforward way that controls the reaction between oxygen gas and metal vapor source in the light of vapor-liquid-solid and vapor-solid mechanisms [42, 43]. CVD involves the process of growing the nanoarchitectured arrays on the substrate surface via the chemical reaction in the gas phase, which is resulted from the vapor with the element of nanoarchitectured arrays and other indispensable gases in the reactive chamber. By using the CVD approach, Si NWs [37] and $\mathrm{V}_{2} \mathrm{O}_{5} / \mathrm{SnO}_{2} \mathrm{NWs}$ [44] could be directly grown on the SS substrate, and $\mathrm{V}_{2} \mathrm{O}_{5}$ nanoribbons [45] would be also done on the $\mathrm{Si}$ substrate. Whilst employing the thermal evaporation technique, Si nanopillars [46] and $\mathrm{SnO}_{2}$ NWs [47] could be orderly grown on the SS substrate. Besides, hydro-/solvothermal growth is a common method of preparing nanoarchitectured arrays grown on the metal or alloy substrate. The process involves the aqueous mixture of soluble metal salt (metal and/or metal-organic) of the precursor material and the treatment of the mixed solution in an autoclave filled under elevated temperature from $100^{\circ} \mathrm{C}$ to $300^{\circ} \mathrm{C}$ and relatively high pressure conditions $>1$ atm. Recently, $\mathrm{MoO}_{x}$ NRs on the $\mathrm{Cu}$ substrate [48], single-crystal mesoporous $\mathrm{Co}_{3} \mathrm{O}_{4}$ nanobelts [49] and $\alpha-\mathrm{Fe}_{2} \mathrm{O}_{3}$ NRs [50] were prepared via the hydro-/solvothermal method. These approaches aforementioned, however, ordinarily require high temperature or high pressure. By comparison, the solution-based method based on a liquid-solid growth mechanism has been extensively exploited for preparing the free-standing nanoarchitectured arrays at the low temperature, which could reduce considerably the complexity and cost of fabrication $[51,52]$. The process is that a piece of substrate immersed in reaction solutions generates a thin film with nanoarchitectured arrays at a low temperature $<100^{\circ} \mathrm{C}$ for a while. For instance, the homogeneous and dense arrays of $\mathrm{ZnO}$ NWs grown on arbitrary substrates were produced by Greene et al. via the liquid-solid growth [53], and Li et al. prepared mesoporous $\mathrm{Co}_{3} \mathrm{O}_{4}$ NWs arrays on the Ti substrate by the ammoniainduced solution growth [54].

Self-etching in Figure 2(b) involves a pure chemical or electrochemical reaction process, in which the surface layer of the conductive substrates is corroded and converted immediately to nanoarchitectured arrays by using the reactions between solutions and the etching materials. Lately, some considerable efforts have been devoted to fabricate ordered 1D Si nanostructured arrays via a metalassisted chemical etching approach $[55,56]$. The etching process included the following aspects: (a) the oxidant was preferentially reduced on the surface of the noble metal; (b) the holes resulted from the reduction of the oxidant on the noble metal surface and were injected into the Si that was in contact with the noble metal; (c) the Si was oxidized and dissolved at the Si/metal interface by HF. Different from the Si etching, a solution-based corrosion is also to prepare nanoarchitectured arrays [57]. Immersed in alkaline solutions, the surface layers of $\mathrm{Cu}$ foil and Ni grid were corroded into $1 \mathrm{D} \mathrm{CuO}$ arrays $[58,59]$ and $\mathrm{Ni}_{3} \mathrm{~S}_{2} \mathrm{NW}$ arrays [60], respectively. In addition, self-organized $\mathrm{TiO}_{2}$ NTs arrays [61, 62 ] had been prepared via electrochemical anodization of $\mathrm{Ti}$ foils by controlling the electrolyte composition as well as the rate at which the resultant oxide was dissolved. To be excited, a novel vapor-phase corrosion strategy had been developed by our group to fabricate $\mathrm{CuO}$ hierarchically mesoporous nanosheet-assembled gearlike pillar arrays (HMNGPAs) and mesoporous nanosheet cluster arrays (MNCAs) [63, 64]. This strategy involved the oxidation, complexation, and thermal decomposition processes and was simple, low-cost, and broadly applicable, providing a new avenue for largescale configuration of nanoarchitectured arrays with unique multifunctional properties.

Template-based growth, just as its name implies, is that the employed materials deposited in the template decorated on the substrate surface via a certain chemical or physical approach are transformed to nanoarchitectured arrays by removing the template membrane, as shown in Figure 2(c). The AAO membrane is the most widely used template, because of its facile preparation and the controllable uniformity pore distribution with lower ohmic drop, validating the homogeneous electrolyte flow. For example, arrays of perpendicular $\mathrm{Cu}$ nanopillars on the $\mathrm{Cu}$ foil substrate were fabricated by Taberna et al. via cathodic electrodepositing of the electrolyte with $\mathrm{Cu}^{2+}$ ion into the pores of $\mathrm{AAO}$ 


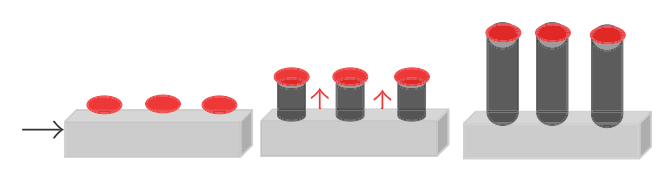

(a)

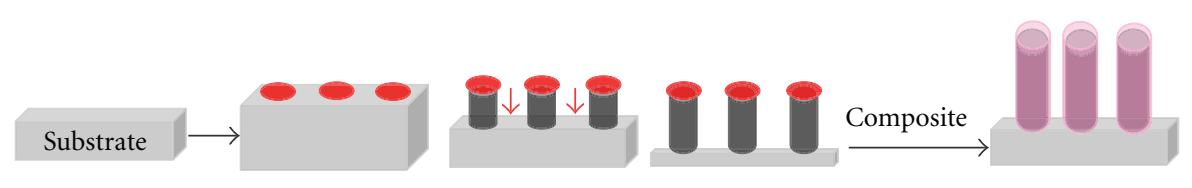

(b)

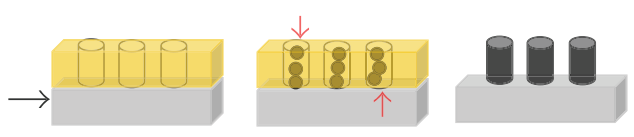

(c)

FIGURE 2: Schematic for the fabrication principle of 3DSNAEs by self-growing (a), self-etching (b), and template-based growth (c).

membrane [65]. Kim et al. [66] prepared vertical arrays of $\mathrm{MnO}_{2} \mathrm{NWs}$ on the Si substrate by the following steps: (a) sputtering a thick aluminum layer on silicon chips, (b) anodizing the aluminum layer, (c) anodic electrodepositing of $\mathrm{MnO}_{2} \mathrm{NWs}$ in the alumina pores, and (d) removing the AAO layer. Besides, by employing the CVD and AAO templates technique, the vertically aligned core-shell Au/CNT$\mathrm{V}_{2} \mathrm{O}_{5} \mathrm{NRs}$ arrays on the $\mathrm{Al}$ substrate had been synthesized by $\mathrm{Kim}$ et al. shown in Figure 3 [67]. Coupled with the previous irrigation from the top of templates, $\mathrm{V}_{2} \mathrm{O}_{5}-\mathrm{TiO}_{2}$ NRs arrays were prepared by a capillary-enforced templatebased method, filling into the pores of a polycarbonate membrane (PC) from the bottom with $\mathrm{VOSO}_{4}$ and $\mathrm{TiOSO}_{4}$ solutions [68].

\section{Selecting Substrate}

The current collector substrate, as a main component of 3DSNAEs, plays a significant role in the configuration and electrochemical performance of 3DSNAEs. The substrate could be classified into three major categories shown in Table 1: cathode substrate with high oxidation voltage ( $\mathrm{Al})$, anodic substrate with high electrochemical stability in a low voltage window $(\mathrm{Cu})$, and multifunctional substrate, on the basis of functions of 3DSNAEs for LIBs.

3.1. Cathode Substrate. Generally, cathode substrate used to load cathode materials $\left(\mathrm{LiCoO}_{2}, \mathrm{LiMn}_{2} \mathrm{O}_{4}\right.$, and $\left.\mathrm{LiFePO}_{4}\right)$ requires high oxidation voltage and high electrochemical stability in a wide voltage window. Al with multiple superiorities, such as high oxidation voltage $\left(5 \mathrm{~V}\right.$ versus $\left.\mathrm{Li} / \mathrm{Li}^{+}\right)$, good electric conductivity, and low price, could be protected by a thin and dense $\mathrm{Al}_{2} \mathrm{O}_{3}$ layer. However, in a low voltage close to $0 \mathrm{~V}$ (versus $\mathrm{Li} / \mathrm{Li}^{+}$), an $\mathrm{Li}-\mathrm{Al}$ alloying process would happen because of the deposition of dissolved $\mathrm{Al}^{3+}$ from the $\mathrm{Al}_{2} \mathrm{O}_{3}$ layer of the $\mathrm{Al}$ foil $[114,115]$. Therefore, $\mathrm{Al}$ is mainly used as the current collector of cathode materials for LIBs. The single-crystal $\mathrm{V}_{2} \mathrm{O}_{5}$ NRs and NTs arrays directly connected to the planar $\mathrm{Al}$ substrate were fabricated by
Wang et al. via template-based electrodeposition and delivered 5 and 1.3 times higher capacity than sol-gel-derived films at the same current density, respectively $[69,116,117]$. Despite the improved electrochemical performance of $\mathrm{V}_{2} \mathrm{O}_{5}$ nanoarchitectured arrays, the planar $\mathrm{Al}$ substrate has limited surface area to provide the limited contact between active materials and substrate. In this regard, Ni NRs arrays were firstly grown on the planar $\mathrm{Al}$ substrate and then coated with $\mathrm{V}_{2} \mathrm{O}_{5}$ to synthesize $\mathrm{Ni}-\mathrm{V}_{2} \mathrm{O}_{5} \cdot n \mathrm{H}_{2} \mathrm{O}$ nanocable arrays, which delivered approximately 10 times higher capacities singlecrystal $\mathrm{V}_{2} \mathrm{O}_{5}$ NRs and 20 times higher than sol-gel-derived $\mathrm{V}_{2} \mathrm{O}_{5}$ films, due to the large surface and short diffusion path offered by the $\mathrm{Ni}-\mathrm{V}_{2} \mathrm{O}_{5} \cdot n \mathrm{H}_{2} \mathrm{O}$ nanocable arrays [118]. Afterwards, Al NRs arrays directly grown on the Al foil to construct $3 \mathrm{D}$ current collectors for LIBs offered high surface area and facilitated the contribution to the capacity of active materials $[119,120]$. For example, a vertically aligned $\mathrm{Au} / \mathrm{CNT}-\mathrm{V}_{2} \mathrm{O}_{5}$ core-shell NRs electrode developed by Kim et al. demonstrated high capacity ( $473.7 \mathrm{mAh} \mathrm{g}^{-1}$ at $1 C$ rate) and excellent rate performance $\left(379.2 \mathrm{mAh} \mathrm{g}^{-1}\right.$ at $10 \mathrm{C}$ rate) owing to the aligned nanostructures with increased reaction sites, facilitated charge transport, and improved mechanical stability [67].

3.2. Anode Substrate. $\mathrm{Cu}$ foil has been extensively used as the current collector of anode materials, because metal $\mathrm{Cu}$ with good conductivity hardly forms the Li-Cu alloy at a low voltage and could be oxidized and dissolved at the high voltage $\left(>3.6 \mathrm{~V}\right.$ versus $\left.\mathrm{Li} / \mathrm{Li}^{+}\right)$[115]. Nickel nanocones arrays (NCAs) which supported $\mathrm{Si}$ anode was firstly constructed by Zhang et al. via the electrodepositing and sputtering techniques and delivered a high capacity of $2400 \mathrm{mAh} \mathrm{g}^{-1}$ at $0.2 \mathrm{C}$ rate over 100 cycles, because Ni NCAs facilitated charge collection and transport, supported the electrode structure, and acted as inactive confining buffers [121]. Thanks to factors that the chemical property of metal $\mathrm{Cu}$ is considerably brisk and easy to be corroded by acid or alkali solutions. The template-based growth is an effective strategy to construct 3DSNAEs on the Cu substrate. 
(a)
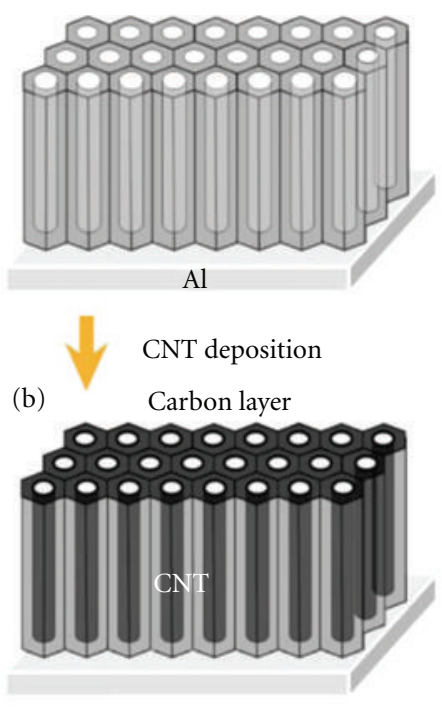

i) ion milling

il) Chemical etching

(c)

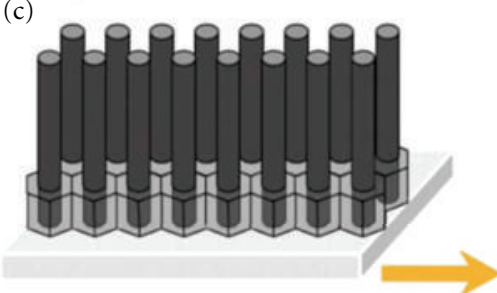

(f)
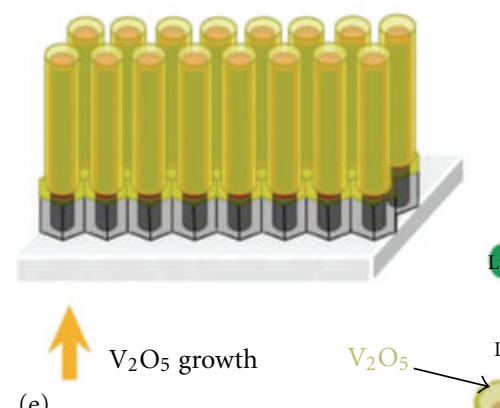

(e)

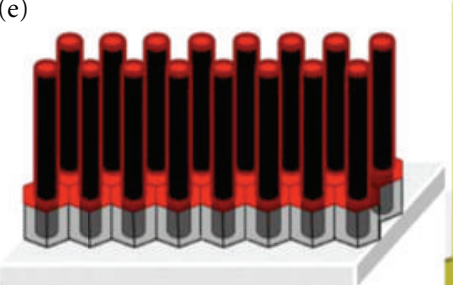

Au coating

(d)

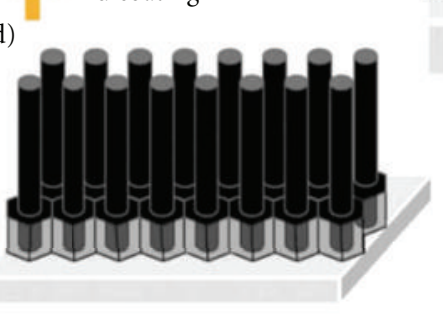

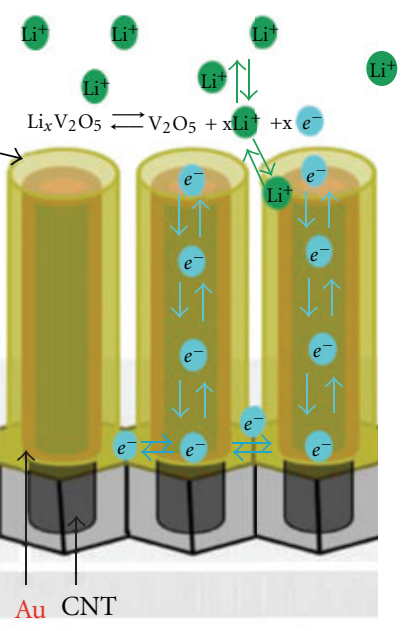

Carbon deposition

FIGURE 3: Schematic of the fabrication process of Au/CNT- $\mathrm{V}_{2} \mathrm{O}_{5}$ core-shell nanorod arrays with the schematized electrochemical reaction involving the nanostructured Li battery electrode [67].

Since Taberna et al. prepared $\mathrm{Cu}$ NRs arrays on the $\mathrm{Cu}$ substrate to construct $\mathrm{Cu} \mathrm{NRs}$ arrays supported $\mathrm{Fe}_{3} \mathrm{O}_{4}$ via AAO template-based electrodeposition [65], many anode materials such as $\mathrm{Cu}-\mathrm{Fe}_{3} \mathrm{O}_{4}[122,123]$, $\mathrm{Cu}-\mathrm{Sn}[74,124]$, $\mathrm{Cu}-\mathrm{Bi}$ [75], $\mathrm{Cu}-\mathrm{Cu}_{3} \mathrm{P}$ [84], and $\mathrm{Cu}-\mathrm{Ni}_{3} \mathrm{Sn}_{4}$ [18] have been developed by the template-based growth. For example, as the anode materials, $\mathrm{Cu}-\mathrm{Ni}_{3} \mathrm{Sn}_{4}$ delivered a capacity of $500 \mathrm{mAh} \mathrm{g}^{-1}$ with no decay over 200 cycles at $0.8 \mathrm{C}$ rate. In addition, solution-based growth is also an efficient way to large-scale fabricateion of 3DSNAEs on the $\mathrm{Cu}$ substrate, due to the easy realization of the preparation conditions. By varying these parameters including the ratio of reaction precursor ions, temperature, and immersing time, $\mathrm{CuO}$ NTs [58], nanobelts [59], NRs [76], $\mathrm{ZnO}$ NRs [77], and $\mathrm{Cu}_{2} \mathrm{~S}$ NWs [83] could be directly grown on the $\mathrm{Cu}$ substrate. At $0.5 \mathrm{C}$ rate, $\mathrm{CuO}$ NRs delivered a high capacity of $650 \mathrm{mAh} \mathrm{g}^{-1}$ with no capacity decay even after 100 cycles. Even at a high rate as high as $20 \mathrm{C}, \mathrm{Cu}_{2} \mathrm{~S}$ NWs were capable of delivering a reversible capacity of $145 \mathrm{mAh} \mathrm{g}^{-1}$.

Metal $\mathrm{Ni}$ is widely available in many forms, such as foil, grid, and felts, and is stable up to $4.5 \mathrm{~V}$ (versus $\mathrm{Li} / \mathrm{Li}^{+}$), after which the electrodissolution of $\mathrm{Ni}$ begins [125]. $\mathrm{Ni}$ is commonly used as the current collector of anode materials. Fan et al. reported that freestanding $\mathrm{Co}_{3} \mathrm{O}_{4}$ nanosheets on the $\mathrm{Ni}$ foil substrate delivered a reversible capacity of $631 \mathrm{mAh} \mathrm{g}^{-1}$ after 50 cycles at a constant current of $150 \mathrm{~mA} \mathrm{~g}^{-1}$ in a fixed voltage window from $2.5 \mathrm{~V}$ to $0.01 \mathrm{~V}$ [87]. Wu et al. prepared interconnected $\mathrm{MnO}_{2} \mathrm{NWs}$ on the $\mathrm{Ni}$ foil substrate by electrodeposition, which delivered reversible capacity of $800 \mathrm{mAh} \mathrm{g}^{-1}$ and with low capacity decay after 100 cycles [86]. Additionally, the oriented $\mathrm{Ni}_{3} \mathrm{~S}_{2} \mathrm{NWs}$ arrays on the $\mathrm{Ni}$ grid substrate fabricated via the solution-based growth showed a reversible capacity of $430 \mathrm{mAh} \mathrm{g}^{-1}$ with the capacity retention $80 \%$ over 100 cycles [60].

$\mathrm{Fe}$ is an inexpensive metal and cannot generate Li-Fe alloy at $0 \mathrm{~V}$ (versus $\mathrm{Li} / \mathrm{Li}^{+}$) during polarization in the cathodic direction; thus, Fe-based alloy substrate could be exploited for loading the metal oxide anode materials to construct 3DSNAEs via the hydro-/solvothermal growth. By controlling the conditions of the hydro-/solvothermal growth, Liu and coworkers have prepared $\mathrm{SnO}_{2}$ NRs [88], $\mathrm{C} / \alpha-\mathrm{Fe}_{2} \mathrm{O}_{3}$ NTs [89], $\mathrm{ZnO} / \mathrm{C}$ NRs [90], and $\mathrm{SnO}_{2} / \mathrm{C}$ NRs [126] directly grown on the Fe-base alloy substrate. The $\mathrm{C} / \alpha-\mathrm{Fe}_{2} \mathrm{O}_{3}$ NTs retained a reversible capacity of as high as $659 \mathrm{mAh} \mathrm{g}^{-1}$ at $0.2 \mathrm{C}$ rate after 150 cycles, and the pristine $\alpha-\mathrm{Fe}_{2} \mathrm{O}_{3}$ NTs maintained only $384 \mathrm{mAh} \mathrm{g}^{-1}$ at the same conditions. Such good electrochemical performance may be attributed to the nanoscale intimate contact of $\alpha-\mathrm{Fe}_{2} \mathrm{O}_{3}$ with 
TABLE 1: A summary of optimizing various electrode materials and suitable strategies to construct 3DSNAEs on various current collector substrates.

\begin{tabular}{|c|c|c|c|c|}
\hline 3DSANEs & Collector & Materials & Growth method & Remark \\
\hline \multirow[t]{2}{*}{ Cathode } & $\mathrm{Al}$ & $\mathrm{V}_{2} \mathrm{O}_{5}[69], \mathrm{LiCoO}_{2}[70]$ & $\begin{array}{l}\text { Template-based chemical or } \\
\text { physical deposition }\end{array}$ & $\begin{array}{l}\text { Needing complicated } \\
\text { synthesis techniques }\end{array}$ \\
\hline & $\begin{array}{c}\text { Sn-doped } \\
\mathrm{In}_{2} \mathrm{O}_{3}(\mathrm{ITO})\end{array}$ & $\mathrm{V}_{2} \mathrm{O}_{5}-\mathrm{TiO}_{2}[68], \mathrm{InVO}_{4}[71]$ & Chemical or physical deposition & \multirow{5}{*}{$\begin{array}{l}\text { It is a technique for large } \\
\text { scale preparation }\end{array}$} \\
\hline \multirow{5}{*}{ Anode } & $\mathrm{Cu}$ & $\begin{array}{l}\text { CNTs }[72], \mathrm{Si}[73], \text { metal }(\mathrm{Sn}, \mathrm{Bi}) \\
{[74,75], \mathrm{MO}(\mathrm{M}=\mathrm{Fe}, \mathrm{Cu}, \mathrm{Zn}, \mathrm{Ni})}\end{array}$ & $\begin{array}{l}\text { Template-based chemical or } \\
\text { physical deposition }\end{array}$ & \\
\hline & & $\begin{array}{l}{[65,76-78] \text {, alloy (SnCo [79], NiSn }} \\
[18,80,81], \text { SiGe }[82]), \mathrm{Cu}_{2} \mathrm{~S}[83], \mathrm{Cu}_{3} \mathrm{P}\end{array}$ & Solution-based growth & \\
\hline & $\mathrm{Ni}$ & $\begin{array}{l}\text { [84], Sn/graphene [85] } \\
\mathrm{Ni}_{3} \mathrm{~S}_{2}[60], \mathrm{MnO}_{2}[86], \mathrm{Co}_{3} \mathrm{O}_{4}[87]\end{array}$ & $\begin{array}{l}\text { Electrodeposition, solution-based } \\
\text { growth }\end{array}$ & \\
\hline & Fe-based alloy & $\mathrm{MO}(\mathrm{M}=\mathrm{Sn}, \mathrm{Fe}, \mathrm{Zn})[88-90]$ & $\begin{array}{l}\text { Hydrothermal, solution-based } \\
\text { growth }\end{array}$ & \\
\hline & Gold & $\mathrm{SnO}_{2}[91], \mathrm{CNT}-\mathrm{MnO}_{2}[92], \mathrm{SnCo}[93]$ & $\begin{array}{l}\text { Template-based chemical or } \\
\text { physical deposition }\end{array}$ & $\begin{array}{l}\text { Needing complicated } \\
\text { synthesis techniques }\end{array}$ \\
\hline \multirow[t]{3}{*}{$\begin{array}{l}\text { Cathode or } \\
\text { anode }\end{array}$} & $\begin{array}{l}\text { The stainless } \\
\text { steel }\end{array}$ & 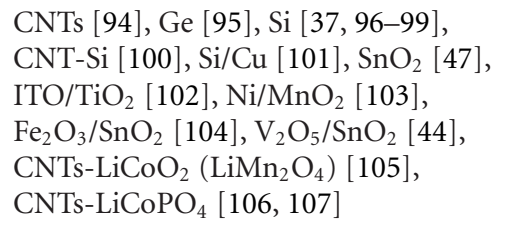 & Chemical/physical vapor deposition & $\begin{array}{l}\text { Needing high } \\
\text { temperature }\end{array}$ \\
\hline & $\mathrm{Ti}$ & $\begin{array}{l}\mathrm{V}_{2} \mathrm{O}_{5}[108], \mathrm{MO}(\mathrm{M}=\mathrm{Ti}, \mathrm{Co}, \mathrm{Fe}, \mathrm{Sn}) \\
{[49,50,62,109]}\end{array}$ & $\begin{array}{l}\text { Anodization, hydro/solvothermal, } \\
\text { Solution-based growth }\end{array}$ & $\begin{array}{l}\text { It is a hope for large scale } \\
\text { preparation }\end{array}$ \\
\hline & $\mathrm{Si}$ & $\begin{array}{l}\mathrm{V}_{2} \mathrm{O}_{5}[45], \mathrm{Si}[56], \mathrm{Si} / \mathrm{NiO}[110], \mathrm{MnO}_{2} \\
{[111], \mathrm{Cu}_{2} \mathrm{O}[112], \mathrm{Sn}[113]}\end{array}$ & $\begin{array}{l}\text { Chemical/physical deposition, } \\
\text { etching }\end{array}$ & $\begin{array}{l}\text { Needing complicated } \\
\text { synthesis techniques }\end{array}$ \\
\hline
\end{tabular}

conductive carbon framework and the unique porous tubular nanostructures readily derived from sacrificial templateaccelerated hydrolysis.

3.3. Dual Functional Substrate. Dual functional substrate, including SS, Ti, Ni, and Si, could act as cathode or anode substrate, owing to the superiorities such as a high oxidation voltage and non-Li-metal alloying process in a low voltage.

As an inert substrate, SS with a high oxidation voltage ( $5 \mathrm{~V}$ versus $\mathrm{Li} / \mathrm{Li}^{+}$) has been widely used as the current collector for LIBs, because the $\mathrm{Cr}$ and Fe oxides on the surface protect the metal bulk from general corrosion. To the best of our knowledge, CVD and physical vapor deposition (PVD) are usually developed to construct 3DSNAEs on the SS substrate. Masarapu et al. found that aligned multiwall carbon nanotubes (MWNTs) on the SS substrate obtained by CVD technique delivered an initial capacity of $132 \mathrm{mAh} \mathrm{g}^{-1}$ at $1 C$ rate and a reversible capacity of $460 \mathrm{mAh} \mathrm{g}^{-1}$ after 1200 cycles, attributing to the morphology of the MWNTs with structural and surface defects and the SS substrate' contribution to capacity [94]. Chan and coworkers prepared a series of Si-based nanoarchitectured arrays on the SS substrate by using $\operatorname{CVD}[37,72,95,97]$ and found that Si NWs exhibited a stable capacity $\sim 3500 \mathrm{mAh} \mathrm{g}^{-1}$ for 20 cycles. Besides, Yan et al. used multistep CVD to construct $\mathrm{V}_{2} \mathrm{O}_{5} / \mathrm{SnO}_{2} \mathrm{NWs}$ with high power density of $60 \mathrm{~kW} \mathrm{~kg}^{-1}$ and energy density of as high as $282 \mathrm{Wh} \mathrm{kg}^{-1}$ [44]. Such excellent performance might be ascribed to the unique core/shell structure that the thin $\mathrm{V}_{2} \mathrm{O}_{5}$ layer was in favor of the fast $\mathrm{Li}^{+}$lithiation/delithiation, and the $\mathrm{SnO}_{2}$ core offered a fast path for electron transportation and also increased the utilization of $\mathrm{V}_{2} \mathrm{O}_{5}$. By employing PVD technique, the vertical Si nanopillars arrays and single-crystal $\mathrm{SnO}_{2} \mathrm{NWs}$ on the SS substrate were also fabricated by Fleischauer et al. [46] and Ko et al. [47]. The $\mathrm{SnO}_{2}$ NWs delivered a high discharge capacity of $510 \mathrm{mAh} \mathrm{g}^{-1}$ after 50 cycles at $1 C$ rate and displayed superior rate capability of $440 \mathrm{mAh} \mathrm{g}^{-1}$ at $10 \mathrm{C}$ rate.

Metal Ti is very resistive to the alkaline ammonia solution and oxidation, does not alloy with lithium at low voltage, and therefore is a good current collector material for LIBs [127]. $\mathrm{V}_{2} \mathrm{O}_{5}$ nanobelt arrays on the $\mathrm{Ti}$ substrate prepared via hydrothermal growth could deliver a reversible capacity of $240 \mathrm{mAh} \mathrm{g}^{-1}$ stably after 50 cycles at the current density of $400 \mathrm{~mA} \mathrm{~g}^{-1}$, and a high rate capacity of $150 \mathrm{mAh} \mathrm{g}^{-1}$ at $4000 \mathrm{~mA} \mathrm{~g}^{-1}$ [108]. And the mesoporous $\mathrm{Co}_{3} \mathrm{O}_{4} \mathrm{NWs}$ arrays on the Ti substrate via solution-based growth exhibited a high reversible capacity of $859 \mathrm{mAh} \mathrm{g}^{-1}$ at the current density of $111 \mathrm{~mA} \mathrm{~g}^{-1}$ and high rate capacities of $450 \mathrm{mAh} \mathrm{g}^{-1}$ at $2220 \mathrm{~mA} \mathrm{~g}^{-1}$ and $240 \mathrm{mAh} \mathrm{g}^{-1}$ at $5550 \mathrm{~mA} \mathrm{~g}^{-1}$ [54]. Whilst directly anodizing and annealing $\mathrm{Ti}$ foil, the self-organized $\mathrm{TiO}_{2}$ NTs on the Ti substrate could be obtained. Ortiz et al. found that the amorphous $\mathrm{TiO}_{2}$ NTs delivered a highest capacity of $77 \mu \mathrm{Ah} \mathrm{cm}^{-2}$, and crystalline $\mathrm{TiO}_{2} \mathrm{NTs}$ had the best capacity retention up to $90 \%$ over 50 cycles [62]. Wei et al. reported that the $\mathrm{TiO}_{2}$ NTs with $50 \mathrm{~nm}$ pore size and $20 \mathrm{~nm}$ thickness showed the highest reversible capacity of 
$180 \mathrm{mAh} \mathrm{g}^{-1}$ over 140 cycles [128]. Liu and coworkers found that $\mathrm{TiO}_{2} \mathrm{NTs}$ annealed at $\mathrm{N}_{2}$ possessed an initial discharge capacity of $163 \mathrm{mAh} \mathrm{g}^{-1}$ and maintained $145 \mathrm{mAh} \mathrm{g}^{-1}$ over 50 cycles and that $\mathrm{TiO}_{2}$ NTs annealed at $\mathrm{CO}$ exhibited an initial capacity of $223 \mathrm{mAh} \mathrm{g}^{-1}$ with the reversible capacity of $179 \mathrm{mAh} \mathrm{g}^{-1}$ at the 50th cycle $[129,130]$. The results might be attributed to the presence of surface defects like Ti-C species and $\mathrm{Ti}^{3+}$ groups with oxygen vacancies, improving the charge-transfer conductivity of the arrays and promoting phase transition.

Although Si could form Li-Si alloy at ca. $0.12 \mathrm{~V}$ (versus $\mathrm{Li} / \mathrm{Li}^{+}$), crystalline Si cores of core-shell crystal-amorphous Si NWs functioned as not active material store but a stable mechanical support [97]. Therefore, the Si substrate can act as a dual functional substrate for loading cathode or anode materials to construct 3DSNAEs. Chan et al. prepared singlecrystal $\mathrm{V}_{2} \mathrm{O}_{5}$ nanoribbons via thermal vapor deposition and found that transformation of $\mathrm{V}_{2} \mathrm{O}_{5}$ into the $\omega-\mathrm{Li}_{3} \mathrm{~V}_{2} \mathrm{O}_{5}$ phase could take place within $10 \mathrm{~s}$ in thin nanoribbons, suggesting a significant increase in battery power density [45]. Liu and coworkers found that $\mathrm{MnO}_{2} \cdot 0.5 \mathrm{H}_{2} \mathrm{O}$ nanowall arrays electrodeposited on the $\mathrm{Si}$ substrate exhibited a reversible capacity of $220 \mathrm{mAh} \mathrm{g}^{-1}$ over 50 cycles at $0.5 \mathrm{C}$ rate and mesoporous $\mathrm{MnO}_{2} \cdot 0.5 \mathrm{H}_{2} \mathrm{O}$ nanowall arrays with $500 \mathrm{~nm}$ thickness delivered a stable capacity of $256 \mathrm{mAh} \mathrm{g}^{-1}$ [111, 131]. Such excellent electrochemical performance might be ascribed to the hierarchically structured macro- and mesoporosity of $\mathrm{MnO}_{2} \cdot 0.5 \mathrm{H}_{2} \mathrm{O}$, which offered a large surface area to volume ratio of favoring interface faradic reactions and shortened solid-state diffusion paths. Moreover, Kim et al. prepared vertical arrays of Sn NWs on the Si substrate via AAO template-based electrodeposition [113], which showed the discharge capacity of $400 \mathrm{mAh} \mathrm{g}^{-1}$ after 15 cycles at the current density of $4200 \mathrm{~mA} \mathrm{~g}^{-1}$.

\section{Structural Configuration}

As electrodes materials of LIBs, nanomaterials could enhance charge/discharge kinetics and improve high Li storage capacity, despite of suffering from low thermodynamic stability and surface side-reactions. Optimizing and designing proper nanoarchitectured arrays to take advantages and restrain disadvantages of electrodes materials are, therefore, of particular importance to the electrochemical properties of 3DSNAEs. Types of the 3DSNAEs structure reviewed here contain homogeneous nanoarchitectured arrays and heterogeneous nanoarchitectured arrays (Figure 4).

\subsection{Homogenous Nanoarchitectured Arrays. Homogenous} nanoarchitectured arrays, namely, single-component nanostructure arrays, mainly include simple nanostructure arrays, nanostructure cluster arrays, and nanostructure gearlike arrays on the basis of the structure characteristic of nanoarchitectured arrays. For this category, nanostructure arrays directly connected to the conductive substrate are used as both the structural support and electroactive materials to alleviate large strain without pulverization and provide good electronic contact and conduction. Electroactive materials of nanoarchitectured arrays, therefore, are considerably rigorous and should possess the merits including a degree of conductivity and easy growth controll.

Simple nanostructure arrays are commonly composed of single-phase 1D NWs, NTs, and NRs arrays directly connected to the conductive substrate. Up to now, the 1D array materials such as $\mathrm{V}_{2} \mathrm{O}_{5}$ nanobelts [108], multiwall carbon nanotubes (MWCNTs) [72, 94], Si NWs [132], Ge NWs [95], Sn NWs [113], $\mathrm{SnO}_{2}$ NRs [88], and $\mathrm{MnO}_{2}$ NWs [86] have been developed to act as the 3DSNAEs with rate capability and cycling stability. $\mathrm{V}_{2} \mathrm{O}_{5}$ nanobelts directly grown on a $\mathrm{Ti}$ substrate based on the hydrogen bonding action delivered high reversible capacity of 650 and $520 \mathrm{mAh} \mathrm{g}^{-1}$ after 50 cycles at the current density of 1.2 and $3 \mathrm{Ag}^{-1}$, respectively. MWCNTs directly grown on a $\mathrm{Cu}$ current collector (MWCNT-on-Cu) in Figure 5 were synthesized by a two-step process of catalyst deposition and CVD and showed a high reversible capacity of $900 \mathrm{mAh} \mathrm{g}^{-1}$ after 50 cycles at $1 C$ rate. Excellent electrochemical properties of MWCNT-on-Cu structure could be ascribed to high Li ion intercalation on the carbon nanotube walls, strongly bonding with the $\mathrm{Cu}$ substrate and good conductivity.

Nanostructure cluster arrays, generally, consist of clusters of assembled NWs, NRs, and nanosheets. Because NWs, NRs and nanosheets are usually inclined to aggregate and form the nanostructure clusters due to their structural instability. Some nanostructure cluster arrays, recently, including network-like and flower-like $\mathrm{CuO}[133,134], \mathrm{CuO}$ MNCAs [64], and $\mathrm{CuO}$ pine-needle-like (PNL) arrays (see Figure 6) [135], have been used as the 3DSNAEs with enhanced lithium storage properties. $\mathrm{CuO}$ MNCAs synthesized by our group exhibited a high reversible capacity of $639.8 \mathrm{mAh} \mathrm{g}^{-1}$ after 100 cycles at $1 C$ rate and a high-rate capability of $548.8 \mathrm{mAh} \mathrm{g}^{-1}$ at $10 \mathrm{C}$ rate. CuO PNL arrays fabricated by our group via an anodic route delivered high rate capacity of 545.9 and $492.2 \mathrm{mAh} \mathrm{g}^{-1}$ at $15 \mathrm{C}$ and $20 \mathrm{C}$ rates and exhibited excellent cyclability of $583.1 \mathrm{mAhg}^{-1}$ after 100 cycles at $2 C$ rate. The enhanced lithium storage properties could be ascribed to the unique nanostructure cluster arrays, which provide suitable branches for lithium storage and suitable free space to facilitate $\mathrm{Li}^{+}$flux across the interface as well as accommodating the large volume variation.

Nanostructure gearlike arrays. In this respect, the size of arrays directly connect to the substrate is mainly microscale, which is stable and easy to controlled synthesis by a simple approach. Furthermore, microarrays are ordinarily assembled by a mass of nanosheets, NWs, or NBs with the same component, in favor of enlarging the contact areas between active materials and electrolyte. The microscale coglike $\mathrm{CuO}$ fabricated by the microemulsion-mediated method exhibited a high reversible capacity of $583 \mathrm{mAh} \mathrm{g}^{-1}$ at a rate of $4 C$ [136]. In our work, CuO HMNGPAs [63] shown in Figure 7 have been synthesized via a novel vaporphase corrosion strategy and exhibited excellent cycling stability of $651.6 \mathrm{mAh} \mathrm{g}^{-1}$ after 100 cycles at $0.5 \mathrm{C}$ rate and high-rate capability of $561.6 \mathrm{mAh} \mathrm{g}^{-1}$ at $10 \mathrm{C}$ rate, because the unique HMNGPAs consisting of numerous gearlike pillars assembled by nanosheets could take full advantage of both micro and nano, namely, micropillars with structural 


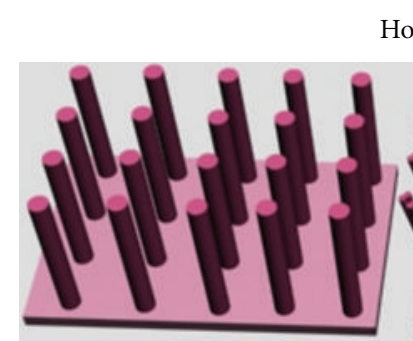

(a)

Homogenous nanoarchitectured arrays

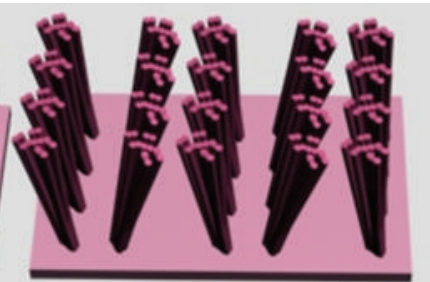

(b)

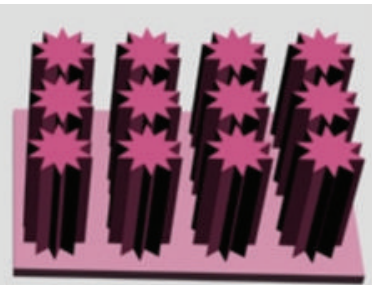

(c)

FIGURE 4: Schematic of homogenous nanoarchitectured arrays. (a) Simple nanostructure arrays, (b) nanostructure cluster arrays, and (c) nanostructure gearlike arrays.
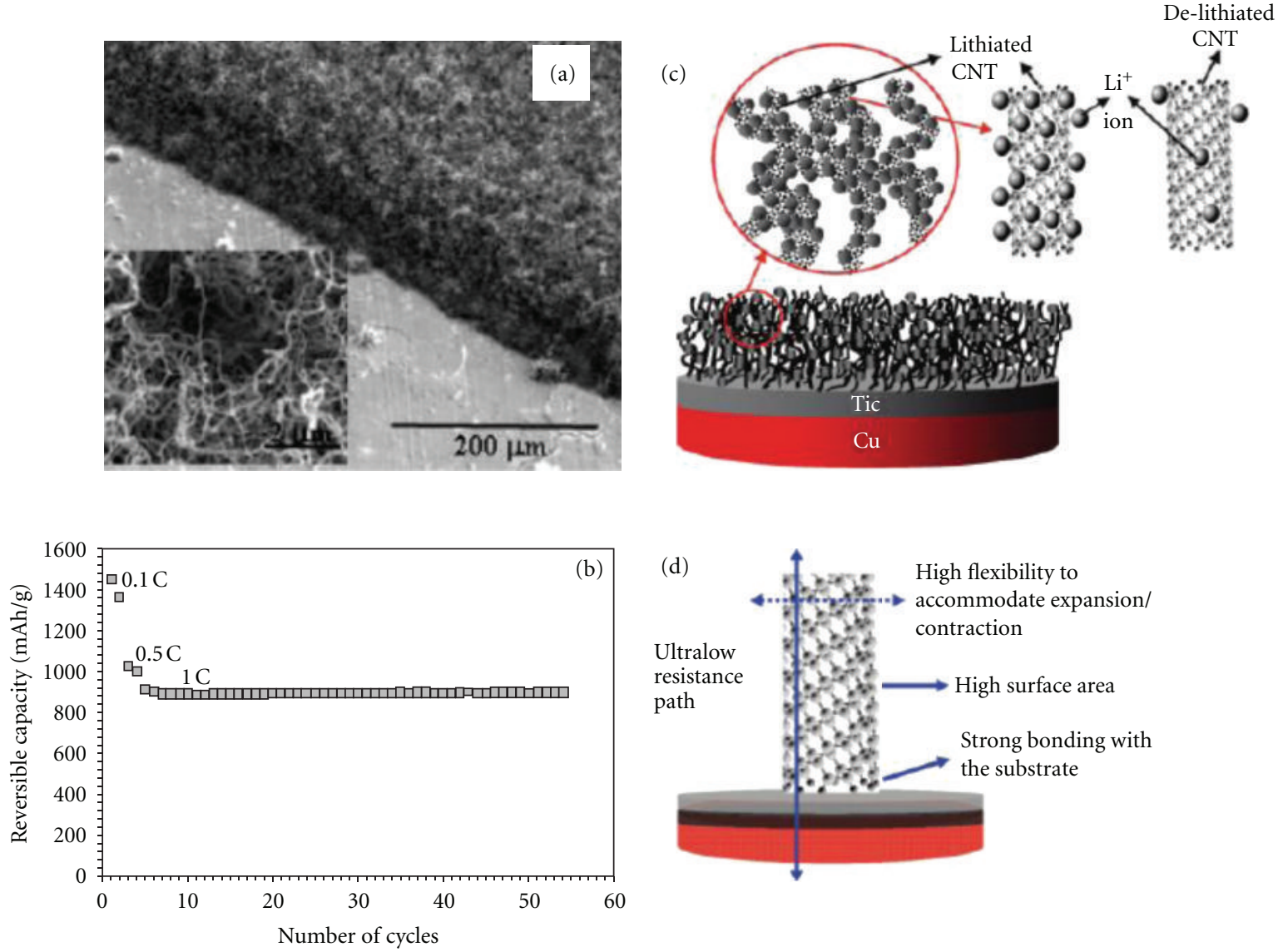

Figure 5: (a) SEM images of the as-grown MWCNT-on-Cu structure. (b) Exceptional stability of the reversible capacity of the MWCNTon- $\mathrm{Cu}$ anode in long-run, at $1 C$ rate. (c) A schematic of the proposed lithiation/delithiation mechanism. (d) A schematic of the proposed anode structure [72].

stability and mesoporous nanosheets with high lithiumstorage sites.

4.2. Heterogeneous Nanoarchitectured Arrays. Heterogeneous nanoarchitectured array are hybrid nanostructure arrays with multinanocomponents each tailored to satisfy different demands such as high energy density, high conductivity, and excellent mechanical stability. On the basis of the structural characteristic, heterogeneous nanoarchitectured arrays could be classified to six types, including (a) simple heterogeneous nanostructure arrays, (b) coaxial or core/shell heterogeneous nanostructure arrays, (c) semicoated grenadelike heterogeneous nanostructure arrays, (d) dispersed heterogeneous nanostructure arrays, (e) branched heterogeneous nanostructure arrays, and (h) folded heterogeneous nanostructure arrays (Figure 8).

4.2.1. Simple Heterogeneous Nanostructure Arrays. Generally, this kind of structure is composed of 1D array structures with two or more components used as active materials, on the basis of the dual lithium insertion/desertion mechanism. $\mathrm{V}_{2} \mathrm{O}_{5}-\mathrm{TiO}_{2} \mathrm{NRs}$ arrays with molar ratio 


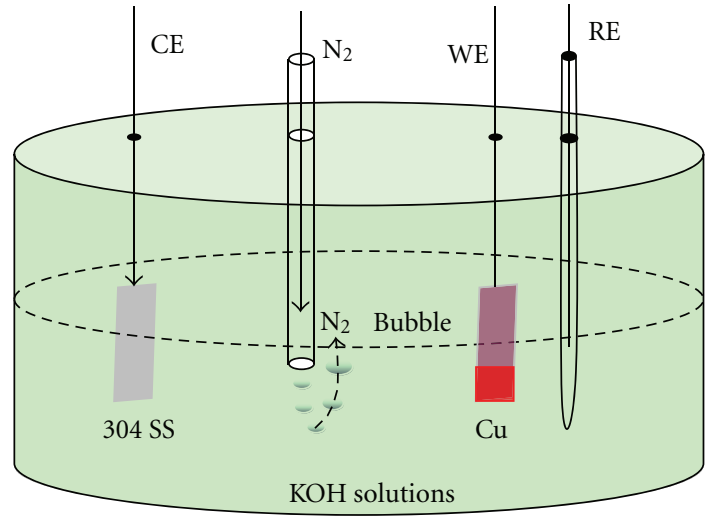

(a)

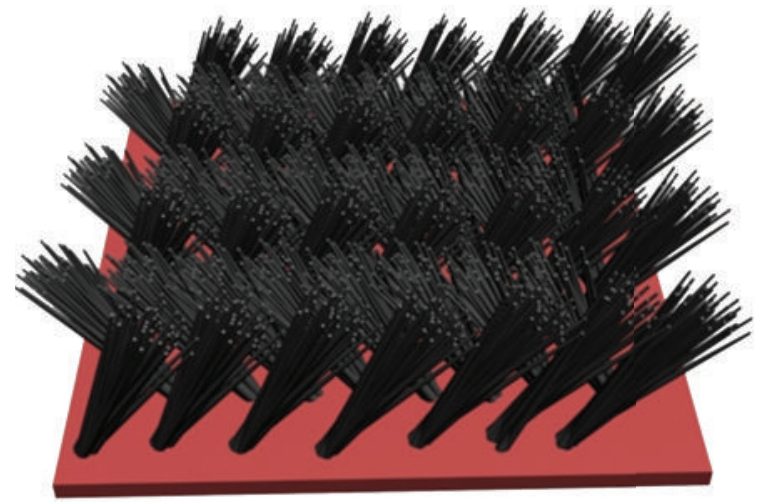

(c)

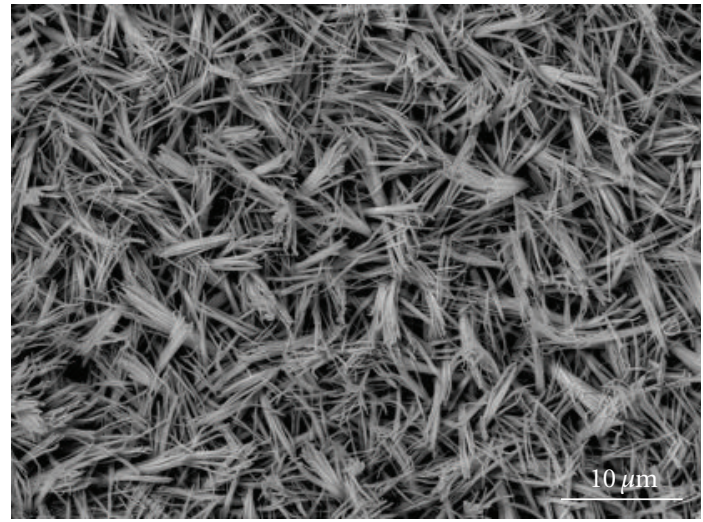

(b)

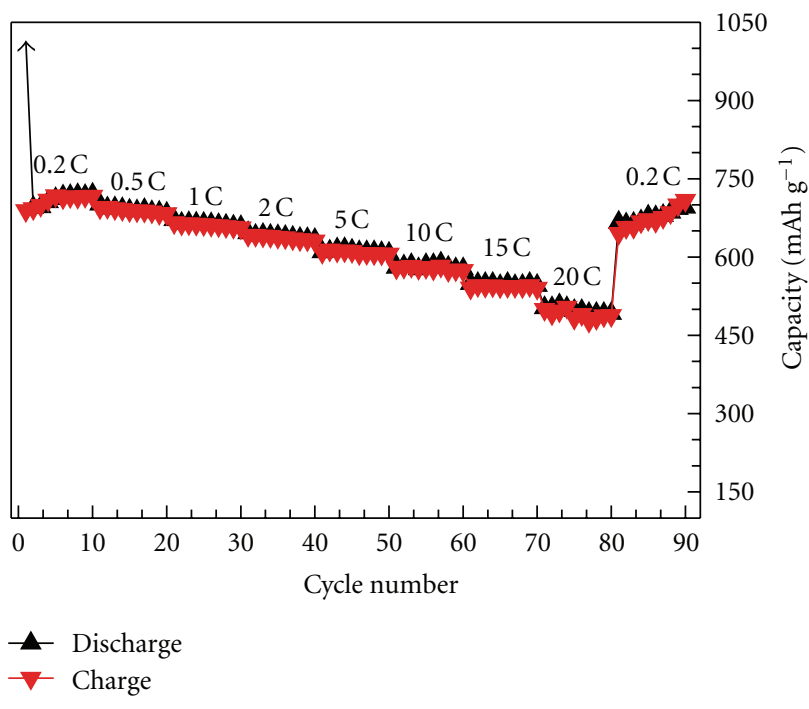

(d)

Figure 6: (a) A schematic of the cell used for the preparation of $\mathrm{Cu}(\mathrm{OH})_{2}$ PNL arrays, wherein $\mathrm{CE}$, WE, and RE represent the counter, working, and reference electrode, respectively. SEM image (b), structural schematic (c), and rate cyclability (d) of CuO PNL arrays gained by annealing $\mathrm{Cu}(\mathrm{OH})_{2}$ PNL arrays [135].

$\mathrm{V} / \mathrm{Ti}=75 / 25$ prepared by Takahashi et al. could deliver 1.5 times discharge capacity of $\mathrm{V}_{2} \mathrm{O}_{5}$ NRs at the current density of $92 \mathrm{~mA} \mathrm{~g}^{-1}$, resulting from the change of crystallinity and interaction forces between adjacent layers in $\mathrm{V}_{2} \mathrm{O}_{5}$ [68]. $\mathrm{SnO}_{2} / \alpha-\mathrm{Fe}_{2} \mathrm{O}_{3}$ NTs arrays fabricated by Zeng et al. showed high areal capacities of $1.289 \mathrm{mAh} \mathrm{cm}^{-2}$ at a current rate of $0.1 \mathrm{~mA} \mathrm{~cm}^{-2}$, possibly due to the synergistic lithium storage of $\mathrm{SnO}_{2}$ and $\alpha-\mathrm{Fe}_{2} \mathrm{O}_{3}$ electroactive materials [137].

\subsubsection{Coaxial or Core/Shell Heterogeneous Nanostructure} Arrays. In this case, the coaxial or core/shell structures refer to $1 \mathrm{D}$ array inner cores coated completely by other materials as shells. The functions of 1D array inner cores and shells can be both the structural support and electroactive materials on the basis of the particularity of 1D array directly connected to the conductive substrate.

While the 1D array inner cores are only used as the structural support, the outer shells are used as the electroactive materials, and the unique structured materials containing
Al NRs- $\mathrm{LiCoO}_{2}$ (see Figure 9) [70], Cu NRs- $\mathrm{Fe}_{3} \mathrm{O}_{4}$ [65], $\mathrm{Cu}-\mathrm{Si}$ nanocable [138], $\mathrm{Cu}-\mathrm{Si}_{1-x} \mathrm{Ge}_{x}$ NWs [82], hybrid ITO/TiO ${ }_{2}$ [102], and $\mathrm{Ni} / \mathrm{Si} \mathrm{NWs}$ [139] exhibit a super high-rate performance. For example, the $\mathrm{Cu}-\mathrm{Si}$ nanocable exhibited a specific capacity as high as $1890 \mathrm{mAh} \mathrm{g}^{-1}$ under a current density of $0.3 \mathrm{Ag}^{-1}$ and $1660 \mathrm{mAh} \mathrm{g}^{-1}$ under a current density of $1.4 \mathrm{~A} \mathrm{~g}^{-1}$. Hybrid $\mathrm{ITO} / \mathrm{TiO}_{2}$ demonstrated an extremely low average capacity fading $\sim 0.1 \%$ per cycle for 1000 cycles at a current density of $60 \mathrm{C}$. The previous excellent lithium storage properties could be related to the unique $\mathrm{Al}, \mathrm{Cu}$, ITO, and $\mathrm{Ni}$ 1D nanostructures directly connected to the conductive substrate, which act as inner cores of electroactive materials and form the 3D conductive network of the current collectors, providing both efficient pathways for ion and electron transport, improving the energy density per unit area.

The other strategy is that the $1 \mathrm{D}$ array inner cores act as the active materials and the shell as conductive agents (amorphous carbon). The semiconductor metal oxides have been usually constructed to the core/shell $\mathrm{Fe}_{2} \mathrm{O}_{3} / \mathrm{C}$ NTs and 


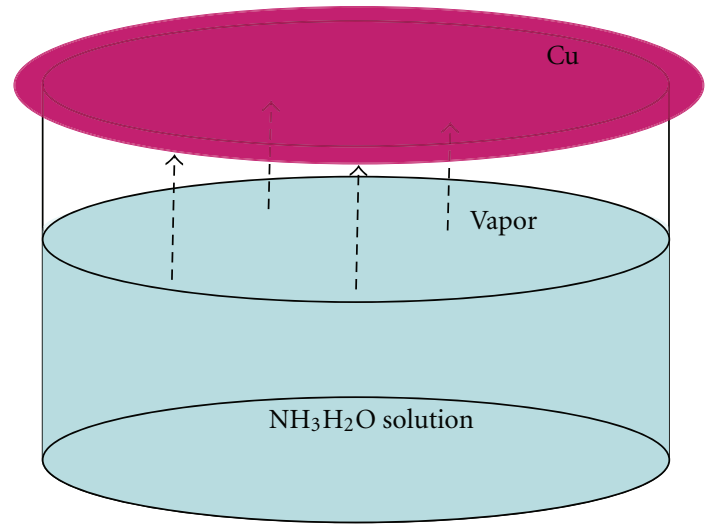

(a)

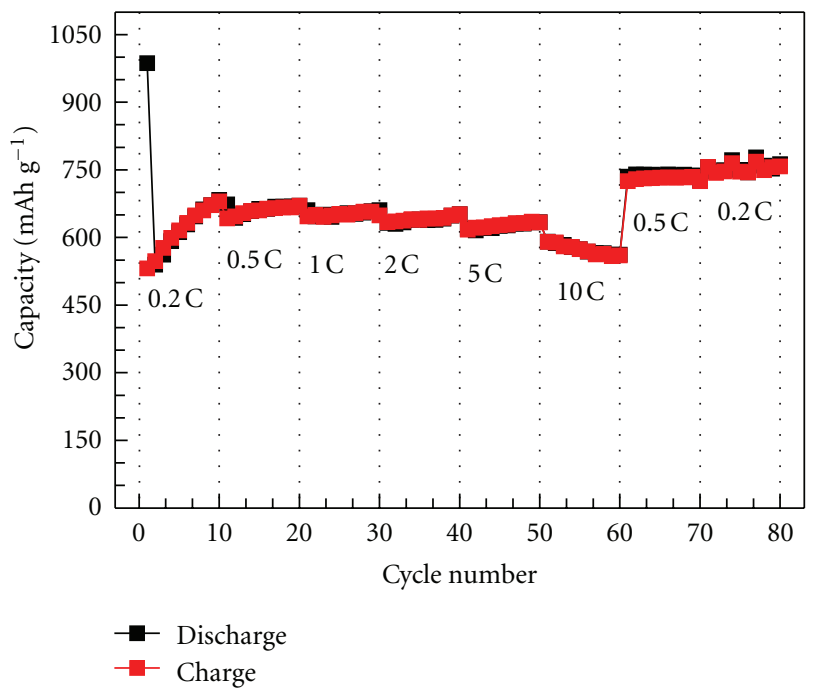

(c)

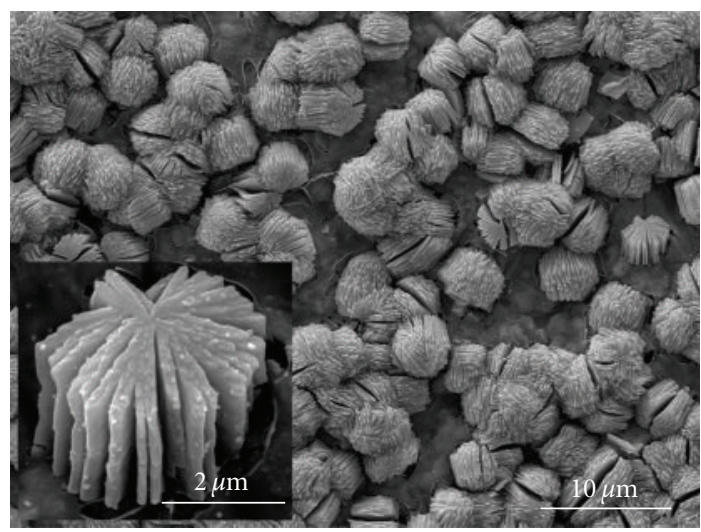

(b)

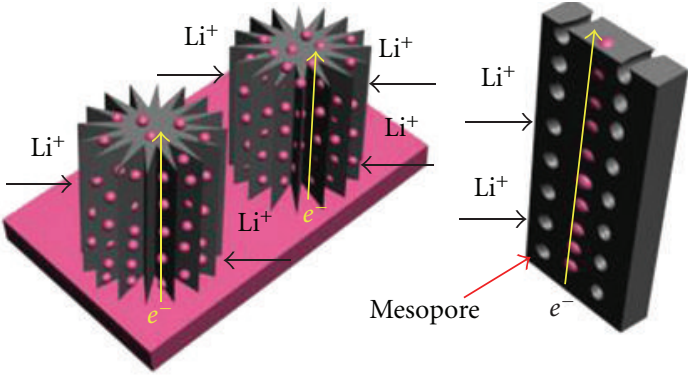

(d)

FIGURE 7: (a) Schematic device of the ammonia vapor-phase corrosion route. SEM images (b), rate cyclability (c), and a schematic diagram of discharge-charge (d) of CuO HMNGPAs [63].

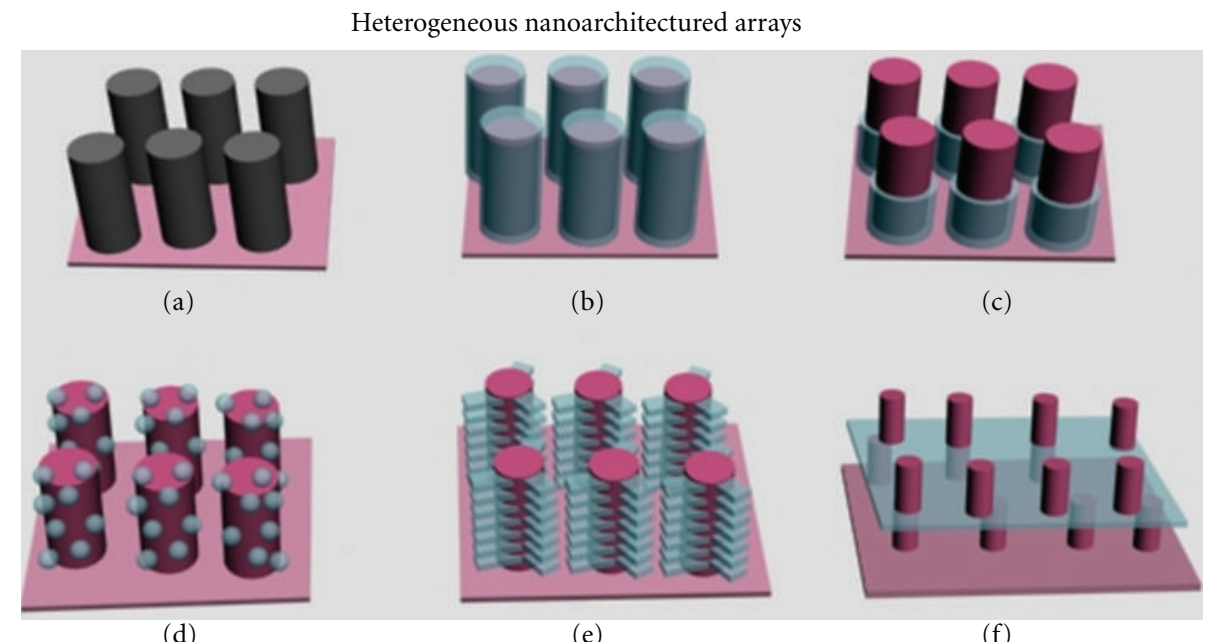

(d)

(e)

(f)

FIGURE 8: Schematic of heterogeneous nanoarchitectured arrays based on structural complexity. (a) Simple heterogeneous nanostructure arrays, (b) coaxial or core/shell heterogeneous nanostructure arrays, (c) semicoated grenadelike heterogeneous nanostructure arrays, (d) dispersed heterogeneous nanostructure arrays, (e) branched heterogeneous nanostructure arrays, and (f) folded heterogeneous nanostructure arrays. 


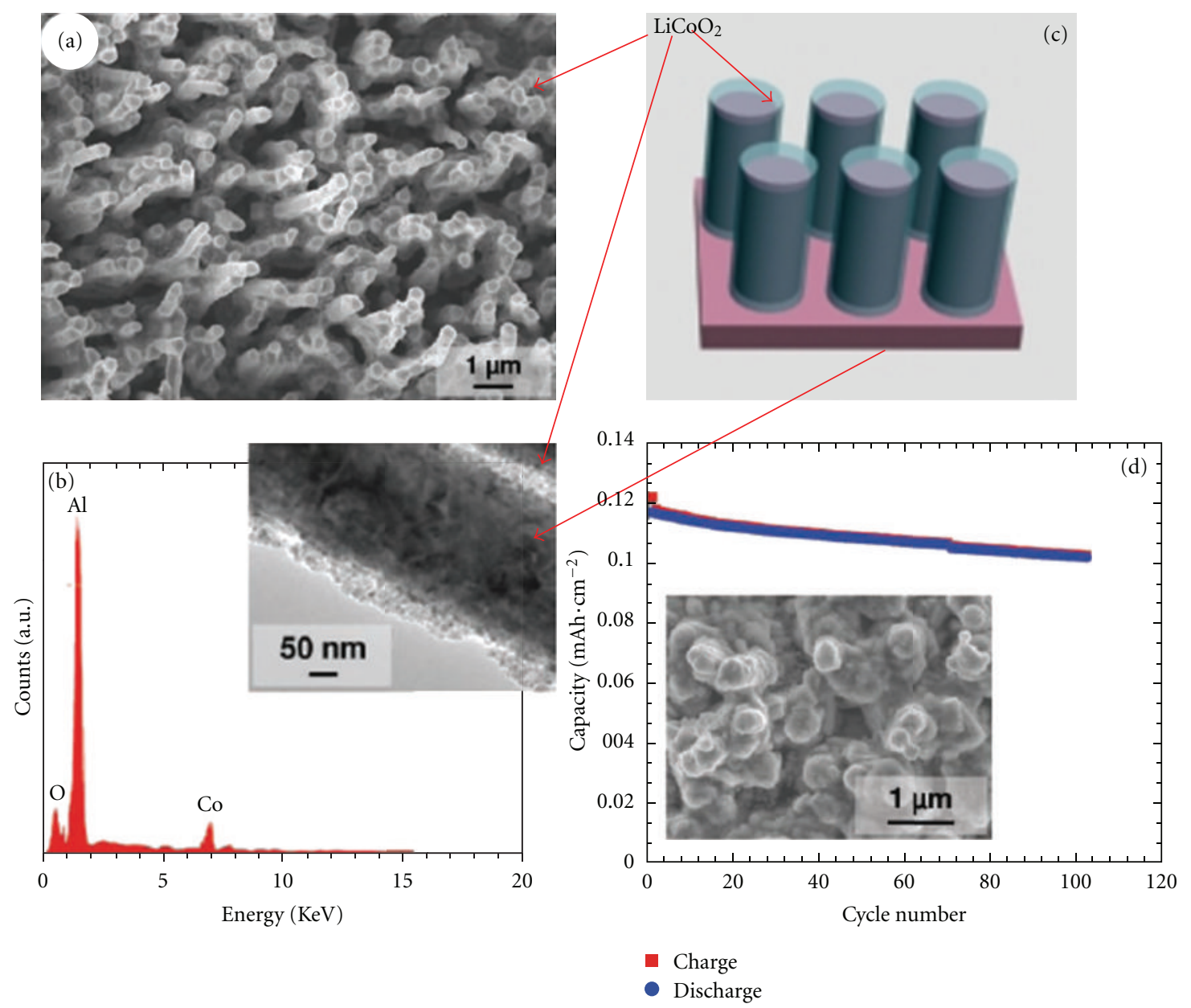

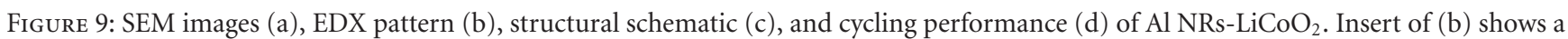

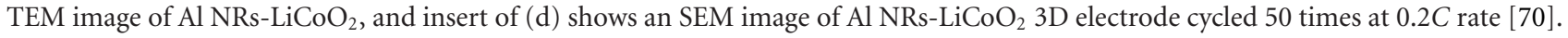

NRs $[50,89], \mathrm{ZnO} / \mathrm{C}$ [90], and $\mathrm{SnO}_{2} / \mathrm{C}$ NRs [126] arrays, wherein metal oxides functioned as both the active core and the structural skeleton, and the carbon shells (nano- $\mathrm{Cu}$ ) are used to improve the conductivity of materials and suppress the volume expansion. $\mathrm{SnO}_{2} / \mathrm{C}$ NRs prepared by a two-step hydrothermal method exhibited a high reversible capacity of $585 \mathrm{mAh} \mathrm{g}^{-1}$ after 50 cycles at $500 \mathrm{~mA} \mathrm{~g}^{-1}$. Furthermore, a new copper-coating layer has better conductivity than carbon and can suppress electrolyte decomposition on the surface of 1D array. Chen et al. found the copper-coated Si NWs showed an initial Coulombic efficiency of $90.3 \%$ at a current density of $210 \mathrm{~mA} \mathrm{~g}^{-1}$ [101].

The third way is that the inner cores and shells are both the active materials to construct the coaxial $\mathrm{SnO}_{2} \mathrm{NWs} / \mathrm{CNTs}$ [91], hybrid $\mathrm{MnO}_{2} / \mathrm{CNTs}$ [92], and C-Si NTs sponge [140]. Hybrid $\mathrm{MnO}_{2} / \mathrm{CNTs}$ delivered the first discharge capacity of $2170 \mathrm{mAh} \mathrm{g}^{-1}$ and a reversible capacity of $\sim 500 \mathrm{mAh} \mathrm{g}^{-1}$ after 15 cycles. This kind of material showed the good charge/discharge performance, due to the dual lithium storage mechanism of insertion/desertion, in which CNTs acted as a highly conductive backbone to accommodate the volume expansion and avoid agglomeration.
4.2.3. Semicoated Grenadelike Heterogeneous Nanostructure Arrays. The grenadelike structure is analogous to the core/ shell structure and composed of inner cores and outer shells. The difference, however, is that the outer shell of grenadelike structures is semicoated. Generally, the inner core is the major component with functional properties, while the outer shell acts as the structural support. Ortiz et al. prepared NWs SnO/NTs $\mathrm{TiO}_{2}$ [141] and $\mathrm{NWs} \mathrm{Fe}_{2} \mathrm{O}_{3} / \mathrm{NTs} \mathrm{TiO}_{2}$ (see Figure 10) [142] in the matrix of $\mathrm{TiO}_{2}$ NTs by anodization and electrodeposition. At the current density of $50 \mu \mathrm{A} \mathrm{cm}{ }^{-2}$, NWs $\mathrm{SnO} / \mathrm{NTs} \mathrm{TiO}_{2}$ exhibited a remarkable reversible capacity of about $140 \mu \mathrm{Ah} \mathrm{cm}^{-2}$ with the capacity retention of ca. $85 \%$ over 50 cycles. The enhanced electrochemical performance could be ascribed to the $\mathrm{TiO}_{2}$ NTs matrix that allows the volume expansion during the $\mathrm{Li}^{+}$insertion and desertion process.

4.2.4. Dispersed Heterogeneous Nanostructure Arrays. In this dispersed structure, nanomaterials are commonly anchored on the surface of $1 \mathrm{D}$ array to be used as the electroactive components or the conductive network for facile electrons transport. While the $1 \mathrm{D}$ array (CNTs and Si NWs) 


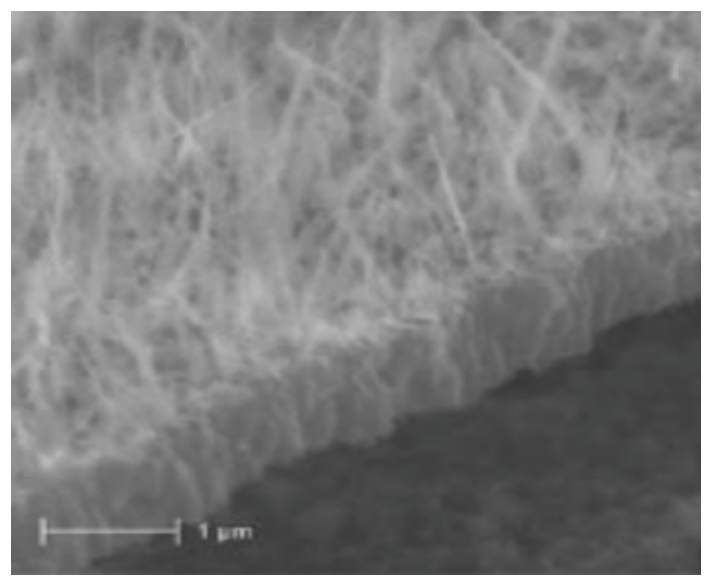

(a)

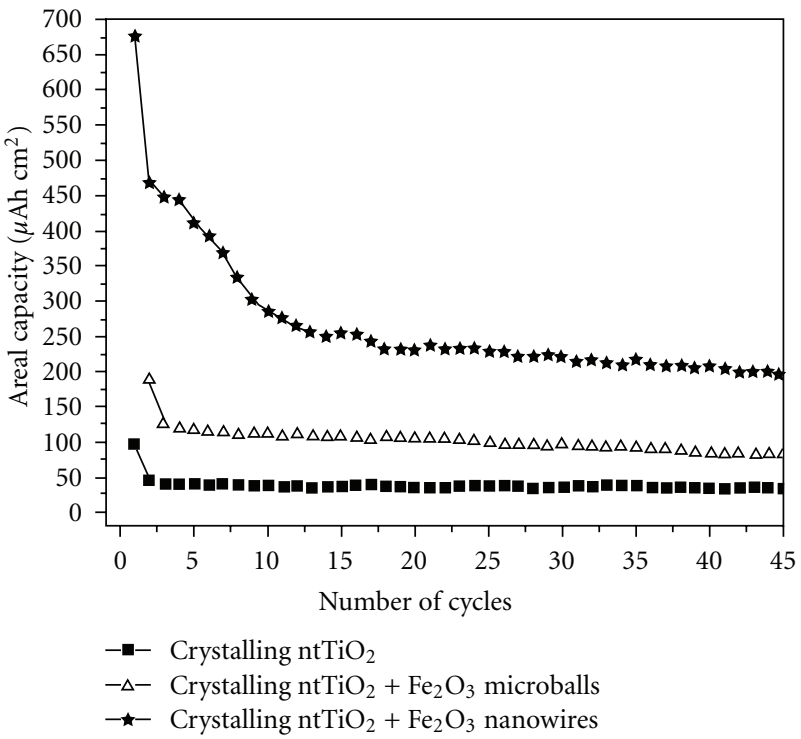

(c)

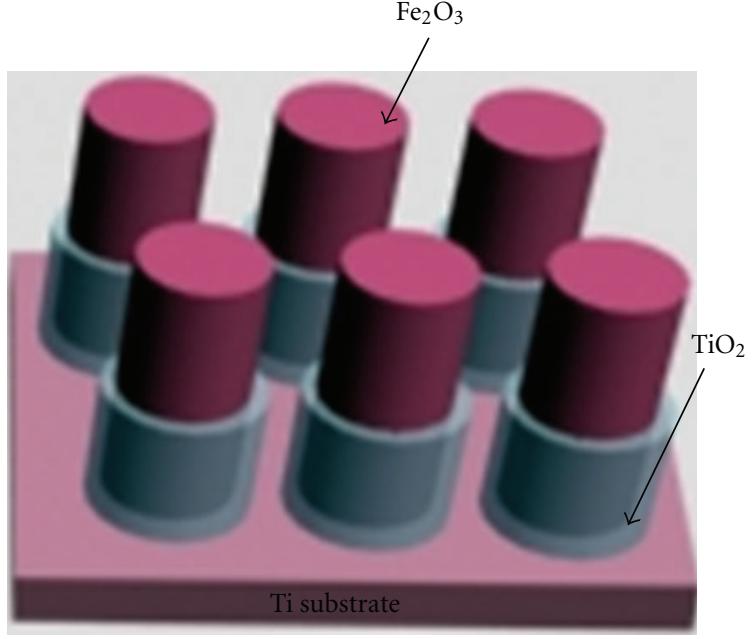

(b)

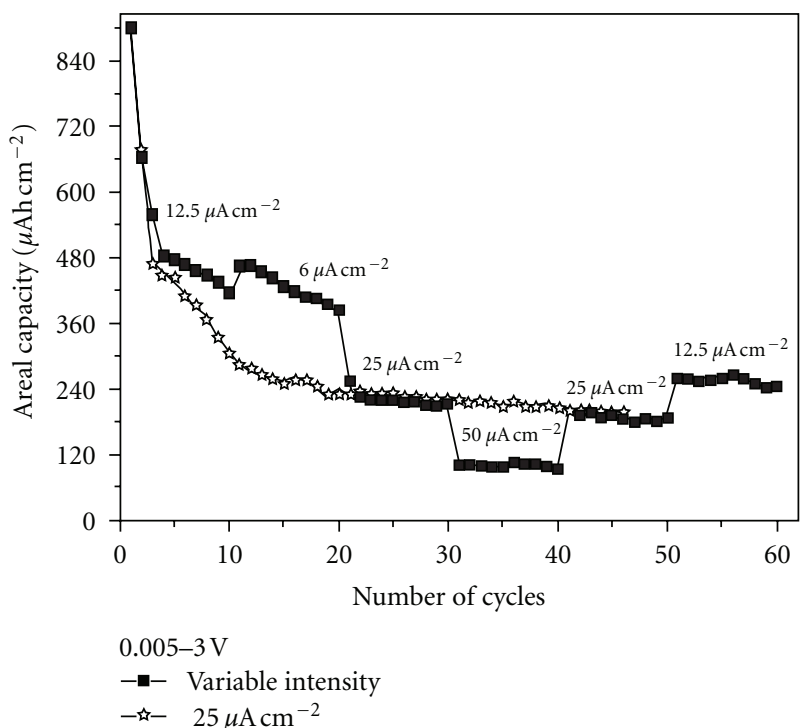

(d)

FIgURE 10: SEM images (a) and structural schematic (b) of nanocomposite NWs $\mathrm{Fe}_{2} \mathrm{O}_{3} / \mathrm{NTs}^{\mathrm{TiO}}$, cycling life (c), and rate performance (d) of nanocomposite electrodes [142].

functioned as the electrical conducting pathway and the stable mechanical support for strain release, the anchored nanomaterials including $\mathrm{LiCoO}_{2}\left(\mathrm{LiMn}_{2} \mathrm{O}_{4}\right)$ [105], $\mathrm{LiCoPO}_{4}$ [106, 107], and NiO NWs [110] acted as the electroactive components. The binder-free $\mathrm{LiCoO}_{2}-3 \mathrm{wt} \%$ SACNTs composites could deliver high reversible capacities of $145.7 \mathrm{mAh} \mathrm{g}^{-1}$ at $0.1 \mathrm{C}$ rate and $130.4 \mathrm{mAh} \mathrm{g}^{-1}$ at $2 \mathrm{C}$ rate. The ordered $\mathrm{NiO}$-coated $\mathrm{Si}$ NWs arrays showed a reversible capacity of $606.13 \mathrm{mAh} \mathrm{g}^{-1}$ at the rate of $50 \mathrm{~mA} \mathrm{~g}^{-1}$ after 30 cycles. While the dispersed nanomaterials (Ag nanoparticles) are mainly applied to improve the conductive and utilization of the active materials, the $\mathrm{Co}_{3} \mathrm{O}_{4}-\mathrm{Ag}$ NWs arrays exhibited more than $82 \%$ capacity retention at the current density of $2000 \mathrm{~mA} \mathrm{~g}^{-1}$ after 20 cycles, in comparison with $74 \%$ capacity retention of the pristine $\mathrm{Co}_{3} \mathrm{O}_{4}$ arrays [143]. When 1D array and dispersed nanomaterials are both used as electroactive materials, these structural materials of VA CNTs-Si $[100,144-146]$ showed high rate capacities of lithium storage. For instance, VA-CNTs/Si arrays shown in Figure 11 via a two-step CVD technique exhibited high discharge capacities of 2980,1890 , and $765 \mathrm{mAh} \mathrm{g}^{-1}$ at $1.3 C$, $5 C$ and $15 C$ rate, respectively.

4.2.5. Branched Heterogeneous Nanostructure Arrays. Being similar to core-shell structure, branched heterogeneous nanostructure arrays, generally, consist of an inner core and outer shell with a branched structure and possess both all desired functions of each component and a strong synergetic enhancement. More specifically, the inner core provides a direct pathway for electron transport, while the outer shell maintains the structural stability of the inner core during the discharge-charge process. The core-shell $\mathrm{Ni} / \mathrm{MnO}_{2}$ hybrid 

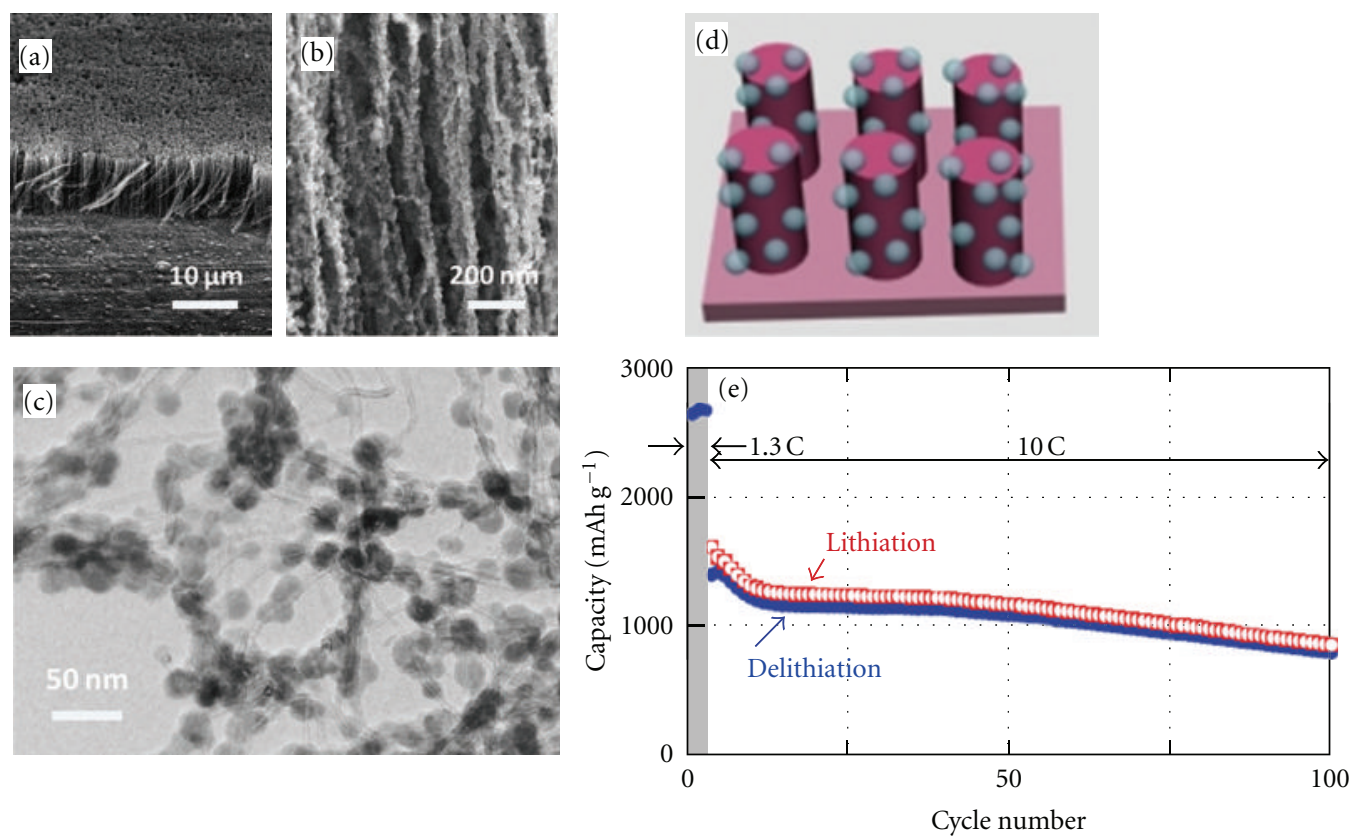

Figure 11: SEM (a, b), TEM (c) images, structural schematic (d), and cycling performance (e) of the as-prepared VA-CNTs/Si arrays on the Si substrate [146].
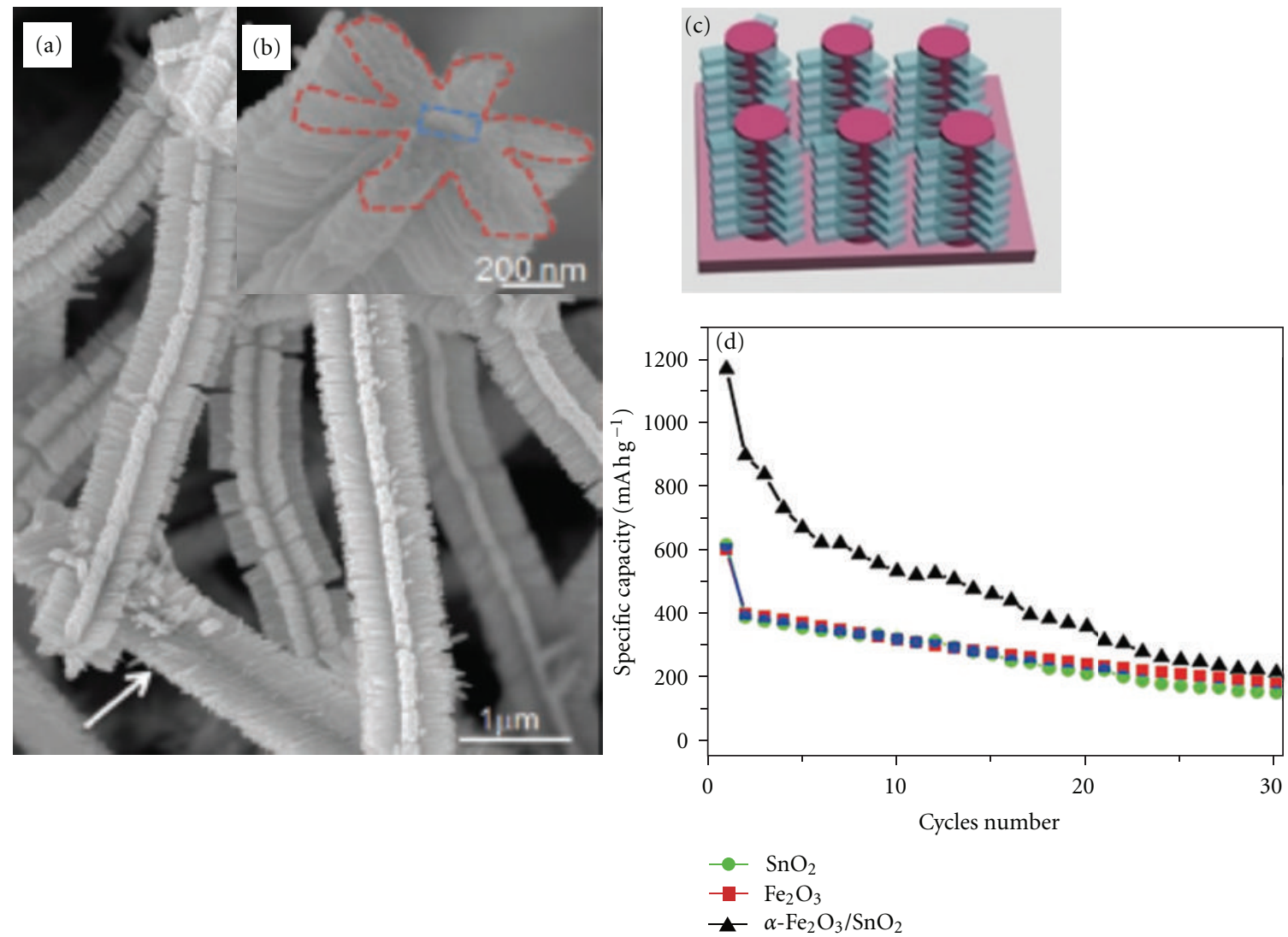

Figure 12: SEM images (a, b) and structural schematic (c) of branched $\alpha$ - $\mathrm{Fe}_{2} \mathrm{O}_{3} / \mathrm{SnO}_{2}$ nanostructures, (d) cycling performance of $\alpha$ $\mathrm{Fe}_{2} \mathrm{O}_{3} / \mathrm{NRs}$ arrays, pristine $\mathrm{SnO}_{2} \mathrm{NWs}$, and $\alpha-\mathrm{Fe}_{2} \mathrm{O}_{3} / \mathrm{SnO}_{2}$ nanostructures at a rate of $1 \mathrm{Ag}^{-1}[104]$. 

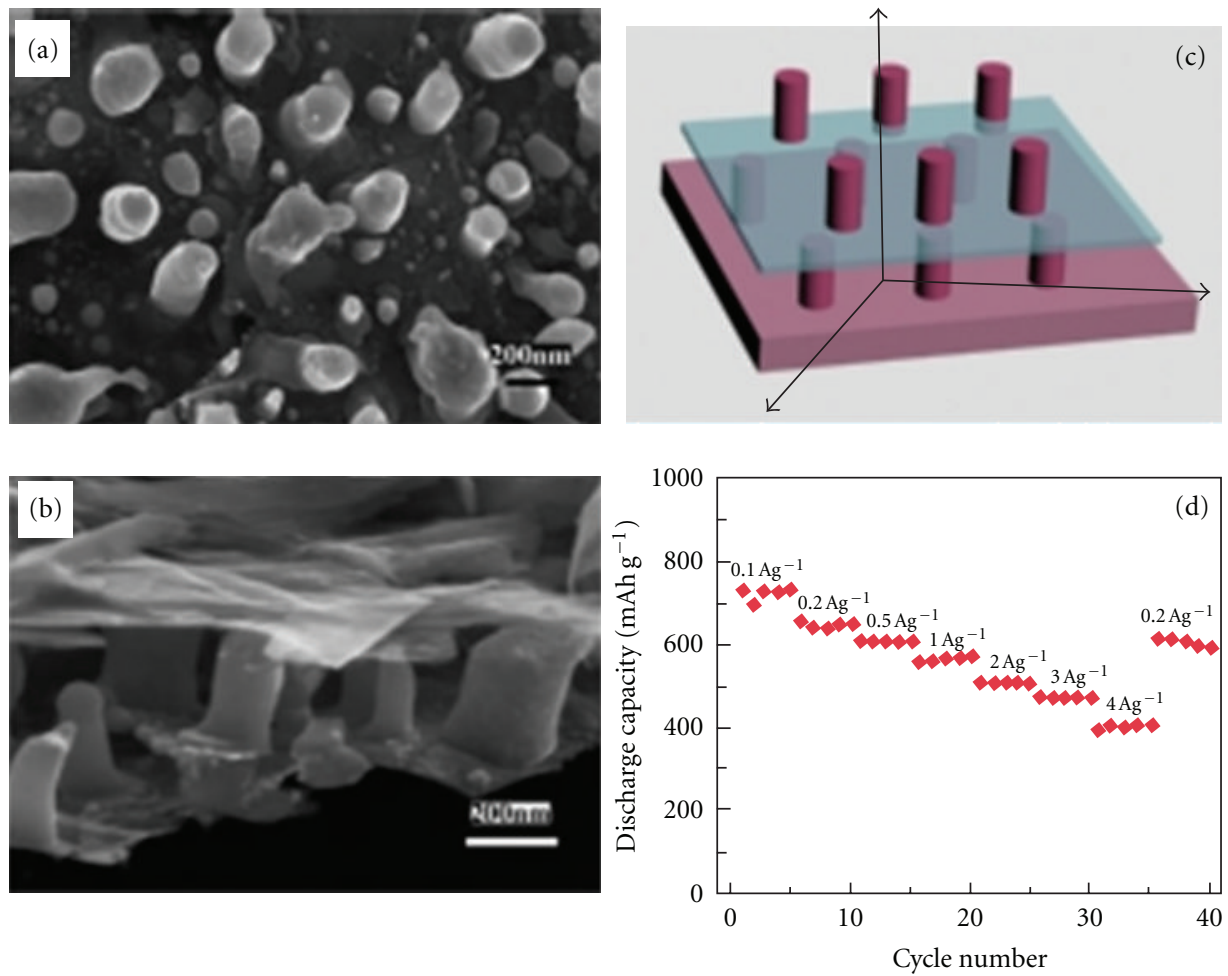

FIgURE 13: SEM images (a, b), structural schematic (c), and rate cyclability (d) of the graphene/Sn-nanopillar nanostructures [85].

[103] fabricated by Jiang et al. via a hydrothermal method delivered reversible capacities of 690,572 , and $445 \mathrm{mAh} \mathrm{g}^{-1}$ at the current density of 1478,2958 , and $5804 \mathrm{mAg}^{-1}$, respectively. Zhou et al. reported that the branched $\alpha$ $\mathrm{Fe}_{2} \mathrm{O}_{3} / \mathrm{SnO}_{2}$ [104] (see Figure 12) prepared by combining a vapor transport deposition and a facile hydrothermal method showed a remarkably improved initial discharge capacity of $1167 \mathrm{mAh} \mathrm{g}^{-1}$, which was about twice the $\mathrm{SnO}_{2}$ NWs $\left(612 \mathrm{mAh} \mathrm{g}^{-1}\right.$ ), and $\alpha-\mathrm{Fe}_{2} \mathrm{O}_{3} \mathrm{NRs}\left(598 \mathrm{mAh} \mathrm{g}^{-1}\right)$. The higher capacity of the branched $\alpha-\mathrm{Fe}_{2} \mathrm{O}_{3} / \mathrm{SnO}_{2}$ is due to that $\alpha-\mathrm{Fe}_{2} \mathrm{O}_{3}$ branches provide new $\mathrm{Li}^{+}$hosts, increase the reversible capacity, and suppress the degradation of the core $\mathrm{SnO}_{2}$.

4.2.6. Folded Heterogeneous Nanostructure Arrays. Even though complicated, the folded heterogeneous nanostructure arrays are ordinarily composed of multilayered 1D nanostructure arrays embedded between $2 \mathrm{D}$ sheets, offering the morphological flexibility to hamper the structural collapse and efficient transport of both $\mathrm{Li}^{+}$and electrons and leading to the excellent electrochemical performance [147]. Ji et al. reported that a multilayered graphene/Sn-nanopillar nanostructure (Figure 13), by using the self-assembly and annealing processes, retained a reversible capacity of 501 and $408 \mathrm{mAh} \mathrm{g}^{-1}$ at a current density of 1 and $5 \mathrm{Ag}^{-1}$ after 35 cycles, respectively, which could be attributed to that both graphene and Sn served as electroactive materials, electronic conductive materials, and mechanically supporting materials [85].

\section{Conclusions and Outlook}

In conclusion, the recent advances in the design, fabrication, and properties of 3DSNAEs with homogeneous or heterogeneous nanoarchitectured structures for LIBs have been reviewed in detail here. Table 1 illustrates an evaluation of optimizing various electrode materials and suitable strategies to construct 3DSNAEs on various current collector substrates. From an industrial perspective, solution-based growth at low temperature and hydrothermal methods are considered to be most promising for constructing 3DSNAEs with proper electrode materials and proper electrode structures.

Evidently, the nanostructure arrays of 3DSNAEs connected to the conductive collector substrate become mechanically unstable when they are grown excessively long in the axial direction. Besides, the electrochemical performance of 3DSNAEs strongly depends on the physical/chemical properties of interface within the heterogeneous nanoarchitectured structures. Systematic/synergetic combining of the mechanical integrity and electrochemical kinetic properties of 3DSNAEs, therefore, will be required to the development of high-performance LIBs.

It can be seen that a large amount of research has been made in designing homogeneous or heterogeneous nanoarchitectured arrays in 3DSNAEs. On one hand, the hybrid structures among 1D NWs, NRs, and 2D nanosheets increase the specific energy density (especially the area and volumetric energy densities) of electrodes, by making full use of voids within the electrodes, and function simultaneously 
as "stabilizers" and "buffers" to the 3DSNAEs with excellent cycling stability. On the other, the heterogeneous components concept opens a promising avenue for designing multifunctional 3DSNAEs by integrating the superiorities of each constituent. Therefore, designing the multifunctional 3DSNAEs with synergic properties by selecting suitable electrode materials and suitable structures is a bright way to address different requirements (high energy density, high conductivity, good mechanical stability, etc.) of superperformance LIBs applied in portable electronic consumer devices, electric vehicles, and large-scale electricity storage.

\section{References}

[1] A. S. Aricò, P. Bruce, B. Scrosati, J. M. Tarascon, and W. Van Schalkwijk, "Nanostructured materials for advanced energy conversion and storage devices," Nature Materials, vol. 4, no. 5, pp. 366-377, 2005.

[2] M. Armand and J. M. Tarascon, "Building better batteries," Nature, vol. 451, no. 7179, pp. 652-657, 2008.

[3] J. B. Goodenough and Y. Kim, "Challenges for rechargeable Li batteries," Chemistry of Materials, vol. 22, pp. 587-603, 2009.

[4] J. M. Tarascon and M. Armand, "Issues and challenges facing rechargeable lithium batteries," Nature, vol. 414, no. 6861, pp. 359-367, 2001.

[5] Annual Energy Outlook, 2010, http://www.eia.gov/ieo.

[6] F. Cheng, J. Liang, Z. Tao, and J. Chen, "Functional materials for rechargeable batteries," Advanced Materials, vol. 23, no. 15, pp. 1695-1715, 2011.

[7] G. Jeong, Y. U. Kim, H. Kim, Y. J. Kim, and H. J. Sohn, "Prospective materials and applications for Li secondary batteries," Energy and Environmental Science, vol. 4, no. 6, pp. 1986-2002, 2011.

[8] M. S. Whittingham, "Lithium batteries and cathode materials," Chemical Reviews, vol. 104, no. 10, pp. 4271-4301, 2004.

[9] M. Okubo, E. Hosono, J. Kim et al., "Nanosize effect on highrate $\mathrm{Li}$-ion intercalation in $\mathrm{LiCoO}_{2}$ electrode," Journal of the American Chemical Society, vol. 129, no. 23, pp. 7444-7452, 2007.

[10] E. Hosono, T. Kudo, I. Honma, H. Matsuda, and H. Zhou, "Synthesis of single crystalline spinel $\mathrm{LiMn}_{2} \mathrm{O}_{4}$ nanowires for a lithium ion battery with high power density," Nano Letters, vol. 9, no. 3, pp. 1045-1051, 2009.

[11] C. S. Johnson, N. Li, C. Lefief, J. T. Vaughey, and M. M. Thackeray, "Synthesis, characterization and electrochemistry of lithium battery electrodes: $\mathrm{XLi}_{2} \mathrm{MnO}_{3 \cdot(1-\mathrm{x})} \mathrm{LiMn}_{0.333} \mathrm{Ni}_{0.333} \mathrm{Co}_{0.333} \mathrm{O}_{2}(0 \leq \mathrm{x} \leq 0.7)$," Chemistry of Materials, vol. 20, no. 19, pp. 6095-6106, 2008.

[12] S. Yang, X. Zhou, J. Zhang, and Z. Liu, "Morphologycontrolled solvothermal synthesis of $\mathrm{LiFePO}_{4}$ as a cathode material for lithium-ion batteries," Journal of Materials Chemistry, vol. 20, no. 37, pp. 8086-8091, 2010.

[13] G. Li, S. Pang, L. Jiang, Z. Guo, and Z. Zhang, "Environmentally friendly chemical route to vanadium oxide singlecrystalline nanobelts as a cathode material for lithium-ion batteries," Journal of Physical Chemistry B, vol. 110, no. 19, pp. 9383-9386, 2006.

[14] H. K. Song, K. T. Lee, M. G. Kim, L. F. Nazar, and J. Cho, "Recent progress in nanostructured cathode materials for lithium secondary batteries," Advanced Functional Materials, vol. 20, no. 22, pp. 3818-3834, 2010.
[15] B. L. Ellis, K. T. Lee, and L. F. Nazar, "Positive electrode materials for Li-Ion and Li-batteries," Chemistry of Materials, vol. 22, no. 3, pp. 691-714, 2010.

[16] N. A. Kaskhedikar and J. Maier, "Lithium storage in carbon nanostructures," Advanced Materials, vol. 21, no. 25-26, pp. 2664-2680, 2009.

[17] H. Kim, M. Seo, M. H. Park, and J. Cho, "A critical size of silicon nano-anodes for lithium rechargeable batteries," Angewandte Chemie, vol. 49, no. 12, pp. 2146-2149, 2010.

[18] J. Hassoun, S. Panero, P. Simon, P. L. Taberna, and B. Scrosati, "High-rate, long-life Ni-Sn nanostructured electrodes for lithium-ion batteries," Advanced Materials, vol. 19, no. 12, pp. 1632-1635, 2007.

[19] C. M. Park, J. H. Kim, H. Kim, and H. J. Sohn, "Li-alloy based anode materials for Li secondary batteries," Chemical Society Reviews, vol. 39, no. 8, pp. 3115-3141, 2010.

[20] P. Poizot, S. Laruelle, S. Grugeon, L. Dupont, and J. M. Tarascon, "Nano-sized transition-metal oxides as negativeelectrode materials for lithium-ion batteries," Nature, vol. 407, no. 6803, pp. 496-499, 2000.

[21] I. A. Courtney and J. R. Dahn, "Electrochemical and in situ X-ray diffraction studies of the reaction of lithium with tin oxide composites," Journal of the Electrochemical Society, vol. 144, no. 6, pp. 2045-2052, 1997.

[22] I. Exnar, L. Kavan, S. Y. Huang, and M. Grätzel, "Novel $2 \mathrm{~V}$ rocking-chair lithium battery based on nano-crystalline titanium dioxide," Journal of Power Sources, vol. 68, no. 2, pp. 720-722, 1997.

[23] J. Cabana, L. Monconduit, D. Larcher, and M. R. Palacín, "Beyond intercalation-based Li-ion batteries: the state of the art and challenges of electrode materials reacting through conversion reactions," Advanced Materials, vol. 22, no. 35, pp. E170-E192, 2010.

[24] L. Ji, Z. Lin, M. Alcoutlabi, and X. Zhang, "Recent developments in nanostructured anode materials for rechargeable lithium-ion batteries," Energy and Environmental Science, vol. 4, no. 8, pp. 2682-2689, 2011.

[25] P. G. Bruce, B. Scrosati, and J. M. Tarascon, "Nanomaterials for rechargeable lithium batteries," Angewandte Chemie, vol. 47, no. 16, pp. 2930-2946, 2008.

[26] F. Cheng, Z. Tao, J. Liang, and J. Chen, "Template-directed materials for rechargeable lithium-ion batteries," Chemistry of Materials, vol. 20, no. 3, pp. 667-681, 2008.

[27] J. W. Long, B. Dunn, D. R. Rolison, and H. S. White, "Threedimensional battery architectures," Chemical Reviews, vol. 104, no. 10, pp. 4463-4492, 2004.

[28] X. W. Lou, L. A. Archer, and Z. Yang, "Hollow micro/nanostructures: synthesis and applications," Advanced Materials, vol. 20, no. 21, pp. 3987-4019, 2008.

[29] Y. K. Sun, S. T. Myung, H. S. Shin, Y. C. Bae, and C. S. Yoon, "Novel core-shell-structured $\mathrm{Li}\left[\left(\mathrm{Ni}_{0.8} \mathrm{Co}_{0.2}\right)_{0.8}\left(\mathrm{Ni}_{0.5} \mathrm{Mn}_{0.5}\right)_{0.2}\right] \mathrm{O}_{2}$ via coprecipitation as positive electrode material for lithium secondary batteries," Journal of Physical Chemistry B, vol. 110, no. 13, pp. 6810-6815, 2006.

[30] L. W. Su, Y. Jing, and Z. Zhou, "Li ion battery materials with core-shell nanostructures," Nanoscale, vol. 3, no. 10, pp. 3967-3983, 2011.

[31] R. Liu, J. Duay, and S. B. Lee, "Heterogeneous nanostructured electrode materials for electrochemical energy storage," Chemical Communications, vol. 47, no. 5, pp. 1384-1404, 2011.

[32] D. R. Rolison, J. W. Long, J. C. Lytle et al., "Multifunctional 3D nanoarchitectures for energy storage and conversion," Chemical Society Reviews, vol. 38, no. 1, pp. 226-252, 2009. 
[33] N. Meethong, H. Y. S. Huang, W. C. Carter, and Y. M. Chiang, "Size-dependent lithium miscibility gap in nanoscale Li 1xFePO4," Electrochemical and Solid-State Letters, vol. 10, no. 5, pp. 134-138, 2007.

[34] L. J. Fu, H. Liu, C. Li et al., "Surface modifications of electrode materials for lithium ion batteries," Solid State Sciences, vol. 8, no. 2, pp. 113-128, 2006.

[35] T. Fang, J. G. Duh, and S. R. Sheen, "Improving the electrochemical performance of $\mathrm{LiCoO}_{2}$ cathode by nanocrystalline $\mathrm{ZnO}$ coating," Journal of the Electrochemical Society, vol. 152, no. 9, pp. A1701-A1706, 2005.

[36] A. I. Hochbaum and P. Yang, "Semiconductor nanowires for energy conversion," Chemical Reviews, vol. 110, no. 1, pp. 527-546, 2010.

[37] C. K. Chan, H. Peng, G. Liu et al., "High-performance lithium battery anodes using silicon nanowires," Nature Nanotechnology, vol. 3, no. 1, pp. 31-35, 2008.

[38] J. Liu, G. Cao, Z. Yang et al., "Oriented nanostructures for energy conversion and storage.," ChemSusChem, vol. 1, no. 8-9, pp. 676-697, 2008.

[39] C. Liu, F. Li, M. Lai-Peng, and H. M. Cheng, "Advanced materials for energy storage," Advanced Materials, vol. 22, no. 8, pp. E28-E62, 2010.

[40] J. Jiang, Y. Li, J. Liu, and X. Huang, "Building onedimensional oxide nanostructure arrays on conductive metal substrates for lithium-ion battery anodes," Nanoscale, vol. 3, no. 1, pp. 45-58, 2011.

[41] Z. R. Dai, Z. W. Pan, and Z. L. Wang, "Novel nanostructures of functional oxides synthesized by thermal evaporation," Advanced Functional Materials, vol. 13, no. 1, pp. 9-24, 2003.

[42] R. S. Wagner, W. C. Ellis, K. A. Jackson, and S. M. Arnold, "Study of the filamentary growth of silicon crystals from the vapor," Journal of Applied Physics, vol. 35, no. 10, pp. 2993 3000, 1964.

[43] A. Sekar, S. H. Kim, A. Umar, and Y. B. Hahn, "Catalystfree synthesis of $\mathrm{ZnO}$ nanowires on Si by oxidation of $\mathrm{Zn}$ powders," Journal of Crystal Growth, vol. 277, no. 1-4, pp. 471-478, 2005.

[44] J. Yan, A. Sumboja, E. Khoo, and P. S. Lee, " $\mathrm{V}_{2} \mathrm{O}_{5}$ loaded on $\mathrm{SnO}_{2}$ nanowires for high rate $\mathrm{Li}$ ion batteries," Advanced Materials, vol. 23, no. 6, pp. 746-750, 2010.

[45] C. K. Chan, H. Peng, R. D. Twesten, K. Jarausch, X. F. Zhang, and Y. Cui, "Fast, completely reversible Li insertion in vanadium pentoxide nanoribbons," Nano Letters, vol. 7, no. 2, pp. 490-495, 2007.

[46] M. D. Fleischauer, J. Li, and M. J. Brett, "Columnar thin films for three-dimensional microbatteries," Journal of the Electrochemical Society, vol. 156, no. 1, pp. A33-A36, 2009.

[47] Y. D. Ko, J. G. Kang, J. G. Park, S. Lee, and D. W. Kim, "Self-supported $\mathrm{SnO}_{2}$ nanowire electrodes for high-power lithium-ion batteries," Nanotechnology, vol. 20, no. 45, Article ID 455701, 2009.

[48] L. Zheng, Y. Xu, D. Jin, and Y. Xie, "Well-aligned molybdenum oxide nanorods on metal substrates: solution-based synthesis and their electrochemical capacitor application," Journal of Materials Chemistry, vol. 20, no. 34, pp. 7135-7143, 2010.

[49] Y. Wang, H. Xia, L. Lu, and J. Lin, "Excellent performance in lithium-ion battery anodes: rational synthesis of $\mathrm{Co}\left(\mathrm{CO}_{3}\right)_{0.5}(\mathrm{OH})_{0.11} \mathrm{H}_{2} \mathrm{O}$ nanobelt array and its conversion into mesoporous and single-crystal $\mathrm{Co}_{3} \mathrm{O}_{4}$, , ACS Nano, vol. 4, no. 3, pp. 1425-1432, 2010.

[50] Y. Song, S. Qin, Y. Zhang, W. Gao, and J. Liu, "Largescale porous hematite nanorod arrays: direct growth on titanium foil and reversible lithium storage," Journal of Physical Chemistry C, vol. 114, no. 49, pp. 21158-21164, 2010.

[51] L. E. Greene, M. Law, D. H. Tan et al., "General route to vertical $\mathrm{ZnO}$ nanowire arrays using textured $\mathrm{ZnO}$ seeds," Nano Letters, vol. 5, no. 7, pp. 1231-1236, 2005.

[52] H. Yu, Z. Zhang, M. Han, X. Hao, and F. Zhu, "A general low-temperature route for large-scale fabrication of highly oriented $\mathrm{ZnO}$ nanorod/nanotube arrays," Journal of the American Chemical Society, vol. 127, no. 8, pp. 2378-2379, 2005.

[53] L. E. Greene, M. Law, J. Goldberger et al., "Low-temperature wafer-scale production of $\mathrm{ZnO}$ nanowire arrays," Angewandte Chemie, vol. 42, no. 26, pp. 3031-3034, 2003.

[54] Y. Li, B. Tan, and Y. Wu, "Mesoporous $\mathrm{Co}_{3} \mathrm{O}_{4}$ nanowire arrays for lithium ion batteries with high capacity and rate capability," Nano Letters, vol. 8, no. 1, pp. 265-270, 2008.

[55] Z. Huang, N. Geyer, P. Werner, J. De Boor, and U. Gösele, "Metal-assisted chemical etching of silicon: a review," Advanced Materials, vol. 23, no. 2, pp. 285-308, 2011.

[56] C. M. Hsu, S. T. Connor, M. X. Tang, and Y. Cui, "Wafer-scale silicon nanopillars and nanocones by Langmuir-Blodgett assembly and etching," Applied Physics Letters, vol. 93, no. 13, Article ID 133109, 2008.

[57] W. Zhang, X. Wen, and S. Yang, "Controlled reactions on a copper surface: synthesis and characterization of nanostructured copper compound films," Inorganic Chemistry, vol. 42, no. 16, pp. 5005-5014, 2003.

[58] J. Y. Xiang, J. P. Tu, X. H. Huang, and Y. Z. Yang, "A comparison of anodically grown $\mathrm{CuO}$ nanotube film and $\mathrm{Cu}_{2} \mathrm{O}$ film as anodes for lithium ion batteries," Journal of Solid State Electrochemistry, vol. 12, no. 7-8, pp. 941-945, 2008.

[59] F. S. Ke, L. Huang, G. Z. Wei et al., "One-step fabrication of $\mathrm{CuO}$ nanoribbons array electrode and its excellent lithium storage performance," Electrochimica Acta, vol. 54, no. 24, pp. 5825-5829, 2009.

[60] C. H. Lai, K. W. Huang, J. H. Cheng et al., "Oriented growth of large-scale nickel sulfide nanowire arrays via a general solution route for lithium-ion battery cathode applications," Journal of Materials Chemistry, vol. 19, no. 39, pp. 7277-7283, 2009.

[61] F. Fabregat-Santiago, E. M. Barea, J. Bisquert, G. K. Mor, K. Shankar, and C. A. Grimes, "High carrier density and capacitance in $\mathrm{TiO}_{2}$ nanotube arrays induced by electrochemical doping," Journal of the American Chemical Society, vol. 130, no. 34, pp. 11312-11316, 2008.

[62] G. F. Ortiz, I. Hanzu, T. Djenizian, P. Lavela, J. L. Tirado, and P. Knauth, "Alternative Li-ion battery electrode based on selforganized titania nanotubes," Chemistry of Materials, vol. 21, no. 1, pp. 63-67, 2009.

[63] X. Chen, N. Q. Zhang, and K. N. Sun, "A vapor-phase corrosion strategy to hierarchically mesoporous nanosheetassembled gearlike pillar arrays for super-performance lithium storage," The Journal of Physical Chemistry C, vol. 116, no. 40, pp. 21224-21231.

[64] X. Chen, N. Q. Zhang, and K. N. Sun, "Facile fabrication of $\mathrm{CuO}$ mesoporous nanosheet cluster array electrodes with super lithium-storage properties," Journal of Materials Chemistry, vol. 22, no. 27, pp. 13637-13642, 2012.

[65] P. L. Taberna, S. Mitra, P. Poizot, P. Simon, and J. M. Tarascon, "High rate capabilities $\mathrm{Fe}_{3} \mathrm{O}_{4}$-based $\mathrm{Cu}$ nanoarchitectured electrodes for lithium-ion battery applications," Nature Materials, vol. 5, no. 7, pp. 567-573, 2006. 
[66] J. H. Kim, T. Ayalasomayajula, V. Gona, and D. Choi, "Fabrication and electrochemical characterization of a vertical array of $\mathrm{MnO}_{2}$ nanowires grown on silicon substrates as a cathode material for lithium rechargeable batteries," Journal of Power Sources, vol. 183, no. 1, pp. 366-369, 2008.

[67] Y. S. Kim, H. J. Ahn, S. H. Nam, S. H. Lee, H. S. Shim, and W. B. Kim, "Honeycomb pattern array of vertically standing core-shell nanorods: its application to Li energy electrodes," Applied Physics Letters, vol. 93, no. 10, Article ID 103104, 2008.

[68] K. Takahashi, Y. Wang, K. Lee, and G. Cao, "Fabrication and $\mathrm{Li}^{+}$-intercalation properties of $\mathrm{V}_{2} \mathrm{O}_{5}-\mathrm{TiO}_{2}$ composite nanorod arrays," Applied Physics A, vol. 82, no. 1, pp. 27-31, 2006.

[69] Y. Wang, K. Takahashi, H. Shang, and G. Cao, "Synthesis and electrochemical properties of vanadium pentoxide nanotube arrays," Journal of Physical Chemistry B, vol. 109, no. 8, pp. 3085-3088, 2005.

[70] M. M. Shaijumon, E. Perre, B. Daffos, P. L. Taberna, J. M. Tarascon, and P. Simon, "Nanoarchitectured 3D cathodes for Li-ion microbatteries," Advanced Materials, vol. 22, no. 44, pp. 4978-4981, 2010.

[71] Y. Wang and G. Cao, "Synthesis and electrochemical properties of $\mathrm{InVO}_{4}$ nanotube arrays," Journal of Materials Chemistry, vol. 17, no. 9, pp. 894-899, 2007.

[72] I. Lahiri, S. W. Oh, J. Y. Hwang et al., "High capacity and excellent stability of lithium ion battery anode using interface-controlled binder-free multiwall carbon nanotubes grown on copper," ACS Nano, vol. 4, no. 6, pp. 3440-3446, 2010.

[73] R. Teki, R. Krishnan, T. C. Parker, T. M. Lu, P. N. Kumta, and N. Koratkar, "Nanostructured silicon anodes for lithium Ion rechargeable batteries," Small, vol. 5, no. 20, pp. 2236-2242, 2009.

[74] L. Bazin, S. Mitra, P. L. Taberna et al., "High rate capability pure Sn-based nano-architectured electrode assembly for rechargeable lithium batteries," Journal of Power Sources, vol. 188 , no. 2, pp. 578-582, 2009.

[75] A. Finke, P. Poizot, C. Guéry et al., "Electrochemical method for direct deposition of nanometric bismuth and its electrochemical properties vs Li," Electrochemical and Solid-State Letters, vol. 11, no. 3, pp. E5-E9, 2008.

[76] Z. Wang, F. Su, S. Madhavi, and X. W. Lou, "CuO nanostructures supported on $\mathrm{Cu}$ substrate as integrated electrodes for highly reversible lithium storage," Nanoscale, vol. 3, no. 4, pp. 1618-1623, 2011.

[77] H. Wang, Q. Pan, Y. Cheng, J. Zhao, and G. Yin, "Evaluation of $\mathrm{ZnO}$ nanorod arrays with dandelion-like morphology as negative electrodes for lithium-ion batteries," Electrochimica Acta, vol. 54, no. 10, pp. 2851-2855, 2009.

[78] Q. Pan, L. Qin, J. Liu, and H. Wang, "Flower-like ZnO-NiOC films with high reversible capacity and rate capability for lithium-ion batteries," Electrochimica Acta, vol. 55, no. 20, pp. 5780-5785, 2010.

[79] G. Ferrara, L. Damen, C. Arbizzani et al., "SnCo nanowire array as negative electrode for lithium-ion batteries," Journal of Power Sources, vol. 196, no. 3, pp. 1469-1473, 2011.

[80] M. Tian, W. Wang, S. H. Lee et al., "Enhancing NiSn nanowire lithium-ion anode performance by tailoring active/inactive material interfaces," Journal of Power Sources, vol. 196, no. 23, pp. 10207-10212, 2011.

[81] M. Tian, W. Wang, Y. J. Wei, and R. G. Yang, "Stable high areal capacity lithium-ion battery anodes based on threedimensional Ni-Sn nanowire networks," Journal of Power Sources, vol. 211, no. 23, pp. 46-51, 2012.
[82] J. Z. Wang, N. Du, H. Zhang et al., "Cu-Si $i_{1-x} \mathrm{Ge}_{\mathrm{x}}$ CoreShell nanowire arrays as three-dimensional electrodes for high-rate capability lithium-ion batteries," Journal of Power Sources, vol. 208, no. 15, pp. 434-439, 2012.

[83] C. H. Lai, K. W. Huang, J. H. Cheng, C. Y. Lee, B. J. Hwang, and L. J. Chen, "Direct growth of high-rate capability and high capacity copper sulfide nanowire array cathodes for lithium-ion batteries," Journal of Materials Chemistry, vol. 20, no. 32, pp. 6638-6645, 2010.

[84] C. Villevieille, F. Robert, P. L. Taberna, L. Bazin, P. Simon, and L. Monconduit, "The good reactivity of lithium with nanostructured copper phosphide," Journal of Materials Chemistry, vol. 18, no. 48, pp. 5956-5960, 2008.

[85] L. W. Ji, Z. K. Tan, T. Kuykendall et al., "Multilayer nanoassembly of Sn-nanopillar arrays sandiwiched between graphene layers for high-capacity lithium storage," Energy \& Environmental Science, vol. 4, no. 9, pp. 3611-3616, 2011.

[86] M. S. Wu, P. C. J. Chiang, J. T. Lee, and J. C. Lin, "Synthesis of manganese oxide electrodes with interconnected nanowire structure as an anode material for rechargeable lithium ion batteries," Journal of Physical Chemistry B, vol. 109, no. 49, pp. 23279-23284, 2005.

[87] Y. Fan, H. Shao, J. Wang, L. Liu, J. Zhang, and C. Cao, "Synthesis of foam-like freestanding $\mathrm{Co}_{3} \mathrm{O}_{4}$ nanosheets with enhanced electrochemical activities," Chemical Communications, vol. 47, no. 12, pp. 3469-3471, 2011.

[88] J. Liu, Y. Li, X. Huang et al., "Direct growth of $\mathrm{SnO}_{2}$ nanorod array electrodes for lithium-ion batteries," Journal of Materials Chemistry, vol. 19, no. 13, pp. 1859-1864, 2009.

[89] J. Liu, Y. Li, H. Fan et al., "Iron oxide-based nanotube arrays derived from sacrificial template-accelerated hydrolysis: large-area design and reversible lithium storage," Chemistry of Materials, vol. 22, no. 1, pp. 212-217, 2010.

[90] J. Liu, Y. Li, R. Ding et al., "Carbon/ZnO nanorod array electrode with significantly improved lithium storage capability," Journal of Physical Chemistry C, vol. 113, no. 13, pp. 53365339, 2009.

[91] N. Zhao, G. Wang, Y. Huang, B. Wang, B. Yao, and Y. $\mathrm{Wu}$, "Preparation of nanowire arrays of amorphous carbon nanotube-coated single crystal $\mathrm{SnO}_{2}$," Chemistry of Materials, vol. 20, no. 8, pp. 2612-2614, 2008.

[92] A. L. M. Reddy, M. M. Shaijumon, S. R. Gowda, and P. M. Ajayan, "Coaxial $\mathrm{MnO}_{2}$ /carbon nanotube array electrodes for high-performance lithium batteries," Nano Letters, vol. 9, no. 3, pp. 1002-1006, 2009.

[93] G. Ferrara, C. Arbizzani, and L. Damen, "High-performing SnCo nanowire electrodes as anodes for lithium-ion batteries," Journal of Power Sources, vol. 211, pp. 103-107, 2012.

[94] C. Masarapu, V. Subramanian, H. Zhu, and B. Wei, "Longcycle electrochemical behavior of multiwall carbon nanotubes synthesized on stainless steel in Li ion batteries," Advanced Functional Materials, vol. 19, no. 7, pp. 1008-1014, 2009.

[95] C. K. Chan, X. F. Zhang, and Y. Cui, "High capacity Li ion battery anodes using Ge nanowires," Nano Letters, vol. 8, no. 1, pp. 307-309, 2008.

[96] L. Hu, H. Wu, S. S. Hong et al., "Si nanoparticle-decorated Si nanowire networks for Li-ion battery anodes," Chemical Communications, vol. 47, no. 1, pp. 367-369, 2011.

[97] L. F. Cui, R. Ruffo, C. K. Chan, H. Peng, and Y. Cui, "Crystalline-amorphous core-shell silicon nanowires for high capacity and high current battery electrodes," Nano Letters, vol. 9, no. 1, pp. 491-495, 2009. 
[98] A. Gohier, B. Laik, J. P. Pereira-Ramos et al., "Influence of the diameter distribution on the rate capability of silicon nanowires for lithium-ion batteries," Journal of Power Sources, vol. 203, pp. 135-139, 2012.

[99] N. Liu, L. B. Hu, M. T. McDowell et al., "Prelithiated silicon nanowires as an anode for lithium ion batteries," ACS Nano, vol. 5, no. 8, pp. 6487-6493, 2011.

[100] L. F. Cui, L. Hu, J. W. Choi, and Y. Cui, "Light-weight freestanding carbon nanotube-silicon films for anodes of lithium ion batteries," ACS Nano, vol. 4, no. 7, pp. 3671-3678, 2010.

[101] H. Chen, Y. Xiao, L. Wang, and Y. Yang, "Silicon nanowires coated with copper layer as anode materials for lithium-ion batteries," Journal of Power Sources, vol. 196, no. 16, pp. 66576662, 2011.

[102] K. S. Park, J. G. Kang, Y. J. Choi, S. Lee, D. W. Kim, and J. G. Park, "Long-term, high-rate lithium storage capabilities of $\mathrm{TiO}_{2}$ nanostructured electrodes using 3D self-supported indium tin oxide conducting nanowire arrays," Energy and Environmental Science, vol. 4, no. 5, pp. 1796-1801, 2011.

[103] J. Jiang, J. H. Zhu, Y. M. Feng et al., "A novel evolution strategy to fabricate a 3D hierarchical interconnected coreshell $\mathrm{Ni} / \mathrm{MnO}_{2}$ hybrid for Li-ion batteries," Chemical Communications, vol. 48, no. 60, pp. 7471-7473, 2012.

[104] W. Zhou, C. Cheng, J. Liu et al., "Epitaxial growth of branched $\alpha-\mathrm{Fe}_{2} \mathrm{O}_{3} / \mathrm{SnO}_{2}$ nano-heterostructures with improved lithium-ion battery performance," Advanced Functional Materials, vol. 21, no. 13, pp. 2439-2445, 2011.

[105] S. Luo, K. Wang, J. P. Wang et al., "Binder-free $\mathrm{LiCoO}_{2} /$ carbon nanotube cathodes for high-performance lithium ion batteries," Advanced Materials, vol. 24, no. 17, pp. 2294-2298, 2012.

[106] J. J. Schneider, J. Khanderi, A. Popp et al., "Hybrid architectures from $3 \mathrm{D}$ aligned arrays of multiwall carbon nanotubes and nanoparticulate $\mathrm{LiCoPO}_{4}$ : synthesis, properties and evaluation of their electrochemical performance as cathode materials in lithium ion batteries," European Journal of Inorganic Chemistry, vol. 211, no. 28, pp. 4349-4359, 2011.

[107] L. Dimesso, C. Förster, W. Jaegermann et al., "Developments in nanostructured $\mathrm{LiMPO}_{4}(\mathrm{M}=\mathrm{Fe}, \mathrm{Co}, \mathrm{Ni}, \mathrm{Mn})$ composites based on three dimensional carbon architecture," Chemical Society Reviews, vol. 41, no. 15, pp. 5068-5080, 2012.

[108] Y. Wang, H. J. Zhang, W. X. Lim, J. Y. Lin, and C. C. Wong, "Designed strategy to fabricate a patterned $\mathrm{V}_{2} \mathrm{O}_{5}$ nanobelt array as a superior electrode for Li-ion batteries," Journal of Materials Chemistry, vol. 21, no. 7, pp. 2362-2368, 2011.

[109] G. Du, Z. Guo, P. Zhang et al., " $\mathrm{SnO}_{2}$ nanocrystals on self-organized $\mathrm{TiO}_{2}$ nanotube array as three-dimensional electrode for lithium ion microbatteries," Journal of Materials Chemistry, vol. 20, no. 27, pp. 5689-5694, 2010.

[110] M. C. Qiu, L. W. Yang, X. Qi, J. Li, and J. X. Zhong, "Fabrication of ordered $\mathrm{NiO}$ coated Si nanowire array films as electrodes for a high performance lithium ion battery," ACS Applied Materials and Interfaces, vol. 2, no. 12, pp. 36143618, 2010.

[111] D. Liu, Q. Zhang, P. Xiao et al., "Hydrous manganese dioxide nanowall arrays growth and their $\mathrm{Li}+$ ions intercalation electrochemical properties," Chemistry of Materials, vol. 20, no. 4, pp. 1376-1380, 2008.

[112] Y. H. Lee, I. C. Leu, C. L. Liao et al., "Fabrication and characterization of $\mathrm{Cu}_{2} \mathrm{O}$ nanorod arrays and their electrochemical performance in Li-ion batteries," Electrochemical and SolidState Letters, vol. 9, no. 4, pp. A207-A210, 2006.

[113] J. H. Kim, S. Khanal, M. Islam, A. Khatri, and D. Choi, "Electrochemical characterization of vertical arrays of tin nanowires grown on silicon substrates as anode materials for lithium rechargeable microbatteries," Electrochemistry Communications, vol. 10, no. 11, pp. 1688-1690, 2008.

[114] S. S. Zhang and T. R. Jow, "Aluminum corrosion in electrolyte of Li-ion battery," Journal of Power Sources, vol. 109, no. 2, pp. 458-464, 2002.

[115] S. T. Myung, Y. Hitoshi, and Y. K. Sun, "Electrochemical behavior and passivation of current collectors in lithium-ion batteries," Journal of Materials Chemistry, vol. 21, no. 27, pp. 9891-9911, 2011.

[116] K. Takahashi, S. J. Limmer, Y. Wang, and G. Cao, "Synthesis and electrochemical properties of single-crystal $\mathrm{V}_{2} \mathrm{O}_{5}$ nanorod arrays by template-based electrodeposition," Journal of Physical Chemistry B, vol. 108, no. 28, pp. 9795-9800, 2004.

[117] K. Takahashi, S. J. Limmer, Y. Wang, and G. Cao, "Growth and electrochemical properties of single-crystalline $\mathrm{V}_{2} \mathrm{O}_{5}$ nanorod arrays," Japanese Journal of Applied Physics Part 1, vol. 44, no. 1 B, pp. 662-668, 2005.

[118] K. Takahashi, Y. Wang, and G. Z. Cao, "Ni- $\mathrm{V}_{2} \mathrm{O}_{5} \cdot \mathrm{nH}_{2} \mathrm{O}$ core-shell nanocable arrays for enhanced electrochemical intercalation," The Journal of Physical Chemistry B, vol. 109, no. 1, pp. 48-51, 2005.

[119] E. Perre, L. Nyholm, T. Gustafsson, P. L. Taberna, P. Simon, and K. Edström, "Direct electrodeposition of aluminium nano-rods," Electrochemistry Communications, vol. 10, no. 10, pp. 1467-1470, 2008.

[120] G. Oltean, L. Nyholm, and K. Edström, "Galvanostatic electrodeposition of aluminium nano-rods for Li-ion threedimensional micro-battery current collectors," Electrochimica Acta, vol. 56, no. 9, pp. 3203-3208, 2011.

[121] S. Zhang, Z. Du, R. Lin et al., "Nickel nanocone-array supported silicon anode for high-performance lithium-ion batteries," Advanced Materials, vol. 22, no. 47, pp. 5378-5382, 2010.

[122] H. Duan, J. Gnanaraj, X. Chen, B. Li, and J. Liang, "Fabrication and characterization of $\mathrm{Fe}_{3} \mathrm{O}_{4}$-based $\mathrm{Cu}$ nanostructured electrode for Li-ion battery," Journal of Power Sources, vol. 185, no. 1, pp. 512-518, 2008.

[123] H. Duan, J. Gnanaraj, and J. Liang, "Synthesis and rate performance of $\mathrm{Fe}_{3} \mathrm{O}_{4}$-based $\mathrm{Cu}$ nanostructured electrodes for Li ion batteries," Journal of Power Sources, vol. 196, no. 10, pp. 4779-4784, 2011.

[124] D. D. Jiang, H. Y. Tian, C. C. Qiu et al., "Electrodeposition and characterization of assembly of $\mathrm{Sn}$ on $\mathrm{Cu}$ nanorods for Li-ion microbattery application," Journal of Solid State Electrochemistry, vol. 15, no. 11-12, pp. 2639-2644, 2011.

[125] H. Lee, J. J. Cho, J. Kim, and H. J. Kim, "Comparison of voltammetric responses over the cathodic region in $\mathrm{LiPF}_{6}$ and LiBETI with and without HF," Journal of the Electrochemical Society, vol. 152, no. 6, pp. A1193-A1198, 2005.

[126] X. Ji, X. Huang, J. Liu et al., "Carbon-coated $\mathrm{SnO}_{2}$ nanorod array for lithium-ion battery anode material," Nanoscale Research Letters, vol. 5, no. 3, pp. 649-653, 2010.

[127] C. Iwakura, Y. Fukumoto, H. Inoue et al., "Electrochemical characterization of various metal foils as a current collector of positive electrode for rechargeable lithium batteries," Journal of Power Sources, vol. 68, no. 2, pp. 301-303, 1997.

[128] Z. Wei, Z. Liu, R. Jiang, C. Bian, T. Huang, and A. Yu, " $\mathrm{TiO}_{2}$ nanotube array film prepared by anodization as anode material for lithium ion batteries," Journal of Solid State Electrochemistry, vol. 14, no. 6, pp. 1045-1050, 2010. 
[129] D. Liu, P. Xiao, Y. Zhang et al., " $\mathrm{TiO}_{2}$ nanotube arrays annealed in $\mathrm{N}_{2}$ for efficient lithium-ion intercalation," Journal of Physical Chemistry C, vol. 112, no. 30, pp. 1117511180, 2008.

[130] D. Liu, Y. Zhang, P. Xiao et al., " $\mathrm{TiO}_{2}$ nanotube arrays annealed in $\mathrm{CO}$ exhibiting high performance for lithium ion intercalation," Electrochimica Acta, vol. 54, no. 27, pp. 68166820, 2009.

[131] D. Liu, B. B. Garcia, Q. Zhang et al., "Mesoporous hydrous manganese dioxide nanowall arrays with large lithium ion energy storage capacities," Advanced Functional Materials, vol. 19, no. 7, pp. 1015-1023, 2009.

[132] K. Kang, H. S. Lee, D. W. Han et al., "Maximum Li storage in Si nanowires for the high capacity three-dimensional $\mathrm{Li}$ ion battery," Applied Physics Letters, vol. 96, no. 5, Article ID 053110, 2010.

[133] H. Wang, Q. Pan, J. Zhao, G. Yin, and P. Zuo, "Fabrication of $\mathrm{CuO}$ film with network-like architectures through solutionimmersion and their application in lithium ion batteries," Journal of Power Sources, vol. 167, no. 1, pp. 206-211, 2007.

[134] Q. Pan, H. Jin, H. Wang, and G. Yin, "Flower-like CuO filmelectrode for lithium ion batteries and the effect of surface morphology on electrochemical performance," Electrochimica Acta, vol. 53, no. 2, pp. 951-956, 2007.

[135] X. Chen, N. Q. Zhang, and K. N. Sun, "Facile fabrication of $\mathrm{CuO} 1 \mathrm{D}$ pine-needle-like arrays for super-rate lithium storage," Journal of Materials Chemistry, vol. 22, no. 30, pp. 15080-15084, 2012.

[136] W. X. Zhang, M. Li, Q. Wang et al., "Hierarchical selfassembly of microscale cog-like superstructures for enhanced performance in lithium-ion batteries," Advanced Functional Materials, vol. 21, no. 8, pp. 3516-3523, 2011.

[137] W. Q. Zeng, F. P. Zheng, R. Z. Li et al., "Template synthesis of $\mathrm{SnO}_{2} / \alpha-\mathrm{Fe}_{2} \mathrm{O}_{3}$ nanotube array for 3D lithium ion battery anode with large areal capacity," Nanoscale, vol. 4, no. 8, pp. 2760-2765, 2012.

[138] F. F. Cao, J. W. Deng, S. Xin et al., "Cu-Si nanocable arrays as high-rate anode materials for lithium-ion batteries," Advanced Materials, vol. 23, no. 38, pp. 4415-4420, 2011.

[139] X. Chen, K. Gerasopoulos, J. Guo et al., "A patterned 3D silicon anode fabricated by electrodeposition on a virusstructured current collector," Advanced Functional Materials, vol. 21, no. 2, pp. 380-387, 2011.

[140] L. B. Hu, H. Wu, Y. F. Gao et al., "Silicon-carbon nanotube coaxial sponge as Li-ion anodes with high areal Capacity," Advanced Energy Materials, vol. 1, no. 4, pp. 523-527, 2011.

[141] G. F. Ortiz, I. Hanzu, P. Lavela, P. Knauth, J. L. Tirado, and T. Djenizian, "Nanoarchitectured $\mathrm{TiO}_{2} / \mathrm{SnO}$ : a future negative electrode for high power density Li-Ion microbatteries," Chemistry of Materials, vol. 22, no. 5, pp. 1926-1932, 2010.

[142] G. F. Ortiz, I. Hanzu, P. Lavela, J. L. Tirado, P. Knauth, and T. Djenizian, "A novel architectured negative electrode based on titania nanotube and iron oxide nanowire composites for Liion microbatteries," Journal of Materials Chemistry, vol. 20, no. 20, pp. 4041-4046, 2010.

[143] H. Cheng, Z. G. Lu, J. Q. Deng, C. Y. Chung, K. Zhang, and Y. Y. Li, "A facile method to improve the high rate capability of $\mathrm{Co}_{3} \mathrm{O}_{4}$ nanowire array electrodes," Nano Research, vol. 3, no. 12, pp. 895-901, 2010.

[144] W. Wang, R. Epur, and P. N. Kumta, "Vertically aligned silicon/carbon nanotube (VASCNT) arrays: hierarchical anodes for lithium-ion battery," Electrochemistry Communications, vol. 13, no. 5, pp. 429-432, 2011.
[145] W. Wang and P. N. Kumta, "Nanostructured hybrid silicon/ carbon nanotube heterostructures: reversible high-capacity lithium-ion anodes," ACS Nano, vol. 4, no. 4, pp. 2233-2241, 2010.

[146] A. Gohier, B. Laïk, K. H. Kim et al., "High rate capacity silicon decorated vertically aligned carbon nanotubes for Liion batteries," Advanced Materials, vol. 24, no. 19, pp. 25922597, 2012.

[147] T. I. Lee, J. P. Jeagal, J. H. Choi et al., "Binder-free and full electrical-addressing free-standing nanosheets with carbon nanotube fabrics for electrochemical applications," Advanced Materials, vol. 23, no. 40, pp. 4711-4715, 2011. 

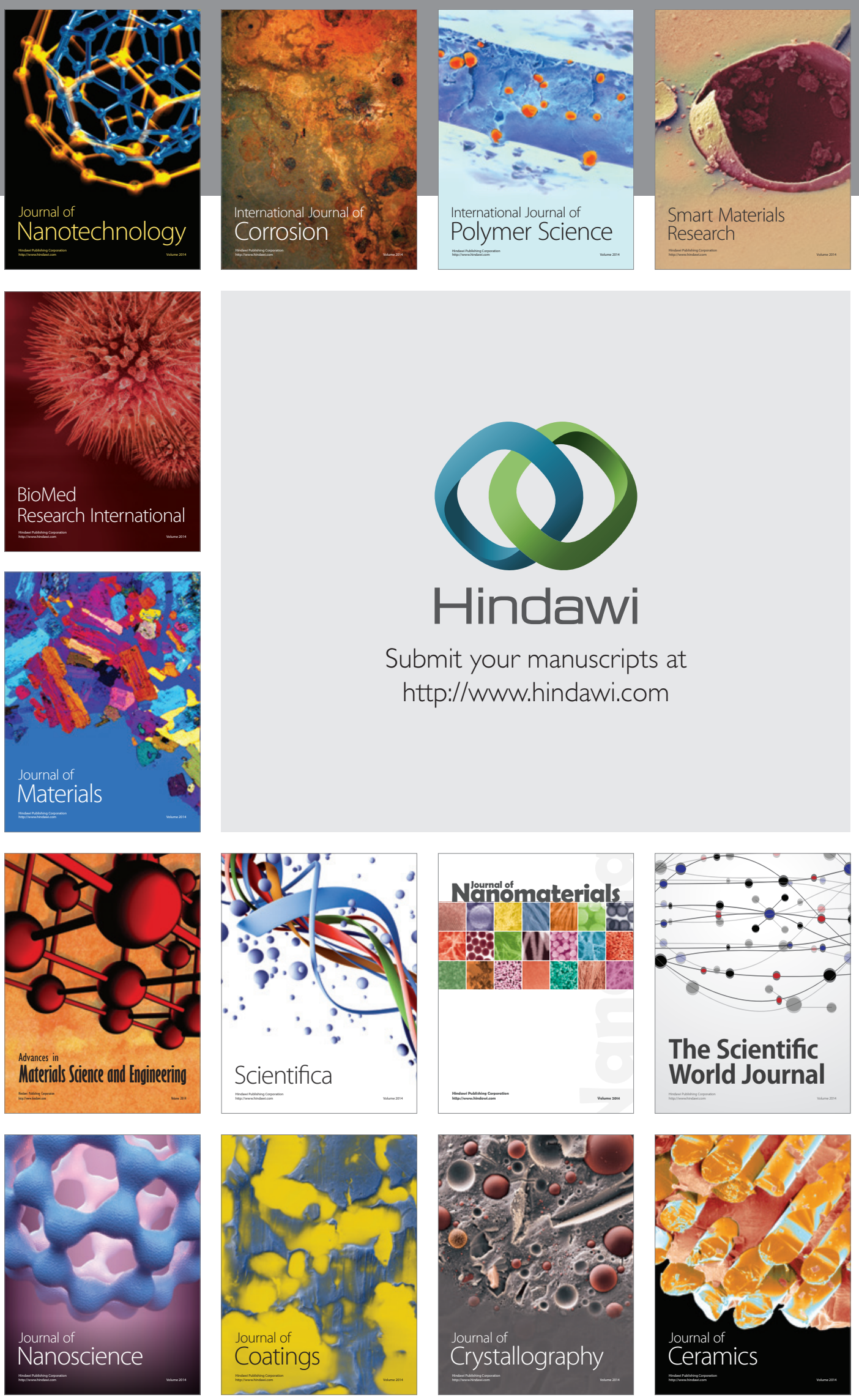

The Scientific World Journal

Submit your manuscripts at

http://www.hindawi.com

\section{World Journal}

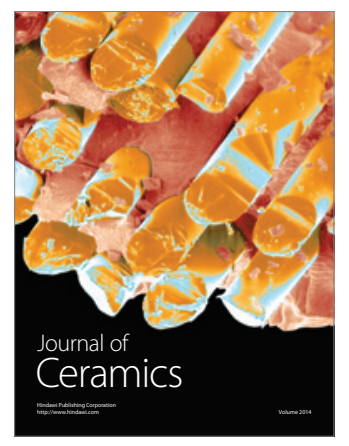

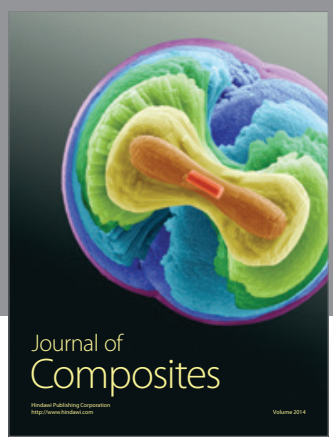
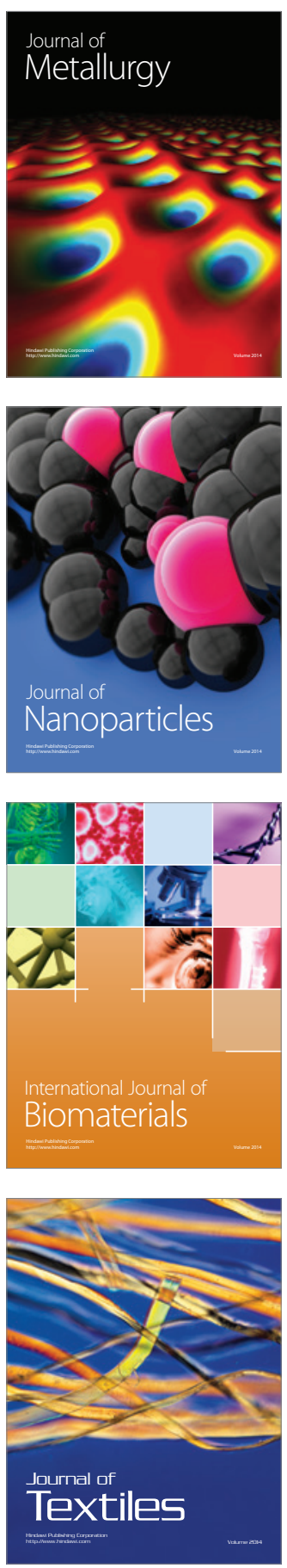